\title{
Microstructure of Kinetic Spray Coatings: A Review
}

\author{
Changhee Lee and Jaeick Kim
}

(Submitted July 16, 2014; in revised form January 7, 2015)

\begin{abstract}
Kinetic spray process has been applied to various industrial fields such as automotive, aviation, and defense industries due to its availability to produce high-performing coating layer. However, since the properties of kinetic-sprayed coating layer are significantly affected by the microstructures of deposit, the microstructures of the deposit should be controlled to acquire advanced coating layer and, accordingly, deep understanding of microstructural evolution must be achieved before controlling the microstructure of the coating layer. This paper gives an overview of contents related to the microstructure of kineticsprayed deposition. The most powerful influencing factors in microstructural evolution of kinetic-sprayed coating layer are instant generation of thermal energy and high-strain, high-strain-rate plastic deformation at the moment of particle impact. A high-density coating layer with low porosity can be produced, although some micro-cracks are occasionally induced at the interparticle boundary or at the inner region of the particles. Also, a microstructure which is distinct from the inner particle region is created in the vicinity of the particle-particle or particle-substrate interface region. However, almost no crystal phase transformation or chemical reaction is induced since the deposited particles are not heated directly by a thermal energy source.
\end{abstract}

Keywords adiabatic shear instability, cold gas dynamic spraying, microstructure

\section{Introduction}

In the kinetic spray, or cold gas dynamic spray process, micron-sized particles are deposited on a substrate by accelerating them to supersonic speeds $(300-1200 \mathrm{~m} / \mathrm{s})$ using converge-diverge de Laval nozzle (Ref 1-8). This induces intimate bonding assisted by adiabatic shear instability at the particle-particle and particle-substrate interface (Ref 9-13). Such characteristic of kinetic spray process, using kinetic energy rather than thermal energy for the particle deposition, provides specific properties to the resultant coating layer (Ref 3, 14-23). Accordingly, kinetic spray process has been applied to various industrial fields such as automotive, aviation, defense, energy, etc. (Ref 24-27). With regard to this, however, the required performances and properties are quite different according to the applications, since not only the purposes of use in each application but also the usage circumstances are dissimilar. Thus, the suitable and optimized properties have to be derived for each of application, respectively, in order to achieve the intended purpose of coating.

At this point, it should be noticed that the properties of kinetic-sprayed coating layer are highly affected by the

Changhee Lee and Jaeick Kim, Kinetic Spray Coating Lab, Division of Materials Science and Engineering, Hanyang University, Seoul 133-791, South Korea. Contact e-mail: chlee@hanyang.ac.kr. microstructures of deposit, although the basic properties of the coating layer are determined by the physical and chemical properties of feedstock materials. For example, Yittria-stabilized Zirconia (YSZ) is usually applied to thermal barrier coating as a form of somewhat porous structure, in order to reduce the thermal conductivity as much as possible (Ref 28). However, most of the mechanical properties of the deposit become degraded along with the increase of porosity because pores in the coating layer eventually mean unbonded interparticle interfaces (Ref 29). To optimize the properties of YSZ thermal barrier coating, the microstructure of the coating needs to be properly porous as much as it can endure external force under its service environment. Likewise, the microstructures of the deposit have to be controlled to obtain high-performing and advanced coating layer. Profound understanding of microstructural evolution must be obtained before able to control the microstructure of the coating layer.

Generally, in the case of kinetic-sprayed deposit, the microstructure is different from that of the coating layer produced by conventional thermal spray processes. The distinctive microstructural evolution in the coating layer is due to high-strain and high-strain-rate plastic deformation of particles, in addition to a large induced quantity of thermal energy near the interface region. Such microstructural evolution is significantly affected by process conditions since process conditions and feedstock particle state determine the in-flight behavior of feedstock particle (Ref 30-33) and, consequently, the deposition behavior of impacted particles (Ref 34-48).

On the basis of the aforementioned things, numerous researches have been dedicated to the understanding of microstructure of kinetic-sprayed deposit. Macroscopically, 
kinetic-sprayed deposits show low porosity and high density with severely deformed and compacted particles (Ref 49-51). Microscopically, the inhomogeneous microstructures are generated between inner and near-interfacial region of deposited particles (Ref 49, 52-54) by an assistance of stored strain-energy-relieving phenomena: grain refinement, dynamic recovery (DRV), dynamic recrystallization (DRX), static recovery (SRV), and static recrystallization (SRX) (Ref 52, 55-62). Additionally, local phase transformations such as amorphization, crystallization (amorphous alloy), and intermetallic compound creation can occur in the vicinity of the interface (Ref 63-65). Above this, post-heat treatment of as-sprayed specimens has significant effect on the microstructure by causing phase transformation or annealing phenomenon (Ref 66-80). However, such researches about the microstructural evolution of kinetic-sprayed deposit have been conducted separately and have never been summarized systematically before, in spite of their importance.

This paper provides an overview of the organized contents related to the microstructure of kinetic-sprayed deposit. The crystal phase compositional change and inhomogeneity of kinetic-sprayed coating are presented; the density, pores, and micro-cracks of the kineticsprayed deposit follow. Finally, the specific microstructural evolution of kinetic-sprayed coatings is discussed and summarized with the examination of some practical cases. The focus of this review is the effect of severe plastic deformation and instantly arising thermal energy at the vicinity of the particle-particle and particle-substrate interface on the microstructure of the kineticsprayed deposits.

\section{Crystal Phase Composition and Reactions}

As it is well known, the kinetic spray process does not involve an external thermal energy, which is the primary characteristic that separates it from the thermal spray process. Consequently, the phase and properties of the asreceived powder are preserved during the deposition stage of the kinetic spray process and, as a result, the desired properties can be retained through the deposition process without any noticeable changes such as oxidation or phase transformation.

However, the presence of chemical reactions or phase changes cannot be completely ruled out. Although the quantity is extremely low, a small number of chemical reactions or phase transformations can occur near the vicinity of the particle-particle or particle-substrate interface due to the instantaneous heat generation at the moment of impact. In addition, after heat treatment, considerable quantity of additional intermetallic compounds can be formed at the interface of the coating substrate between components of the composite.

In this chapter, the phase and chemical reaction of the kinetic-sprayed coating layer will be discussed.

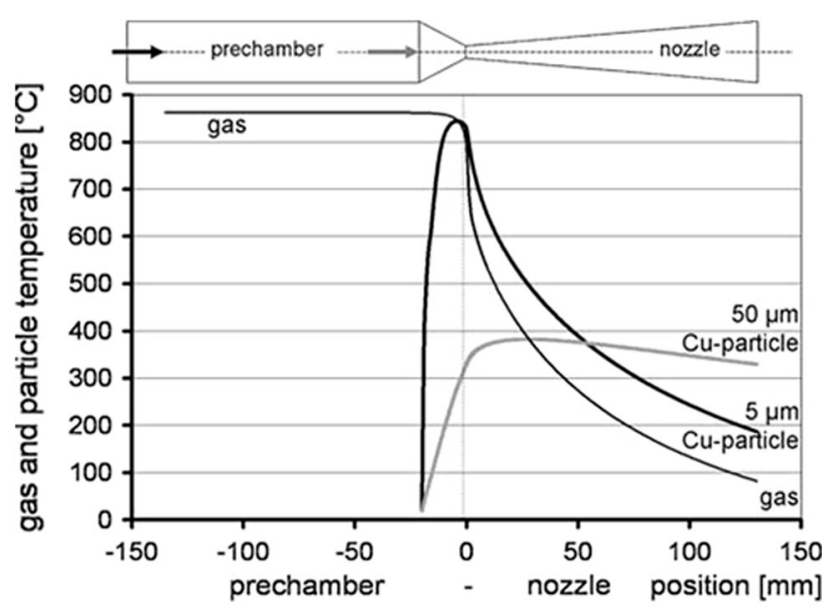

Fig. 1 Numerically calculated $\mathrm{Cu}$ particle temperatures during the flight through the nozzle (nitrogen as process gas, $T_{\text {gas }}=900{ }^{\circ} \mathrm{C}$, $P_{\text {gas }}=40$ bar, isentropic calculation, size of 5 and $\left.50 \mu \mathrm{m}\right)$

\subsection{As-Sprayed Specimens}

In the kinetic spray process, particles are deposited as solid state due to the absence of a heat source such as plasma or arc. Although the process gas used in the kinetic spray is heated to $700-800{ }^{\circ} \mathrm{C}$, this gas temperature setting plays the role of accelerator rather than heater to the particles. Particle heating effect is minimal due to the short residence time of particles and to the cooling of the process gas at the throat of the De Laval nozzle. This is obviously shown in the research of $T$. Schmidt et al. Figure 1 shows the results of numerical simulation of the temperature sequence of in-flight $\mathrm{Cu}$ particle through the nozzle (Ref 81).

Although the initial temperature of the process gas is $900{ }^{\circ} \mathrm{C}$, it can be easily found that the temperature of 5 and $50 \mu \mathrm{m} \mathrm{Cu}$ particle was just $\sim 350$ and $\sim 100{ }^{\circ} \mathrm{C}$ at the exit of the nozzle, respectively. The temperature difference between the 5 and $50 \mu \mathrm{m} \mathrm{Cu}$ particle was caused by higher heat loss of the $5 \mu \mathrm{m} \mathrm{Cu}$ particle due to the particle size effect. The smaller particle was heated more rapidly than the larger particle, but the rate of heat loss was so high that the temperature of the smaller particle decreased immediately due to a high ratio of surface area to volume, according to $T$. Schmidt et al. (Ref 10).

Additionally, according to results from particle impact modeling using ABAQUS conducted by many researchers, the inner region of the particles is not significantly heated relative to the vicinity of the interface between particle-particle and particle-substrate at the moment of impact, where the temperature increases to $0.99 \mathrm{~T}_{\mathrm{m}}$ (Ref 9-13). Thus, in terms of the entire kinetic-sprayed deposit, virtually no phase transformation or chemical reaction (i.e., formation of intermetallic compounds) occurs during the deposition stage. This can be easily verified via a phase analysis of the coating layer. Figure 2 presents a comparison of XRD peaks between the NiTiZrSiSn amorphous alloy feedstock material and the as-sprayed coating layer, which is the result of research (Ref 82). 


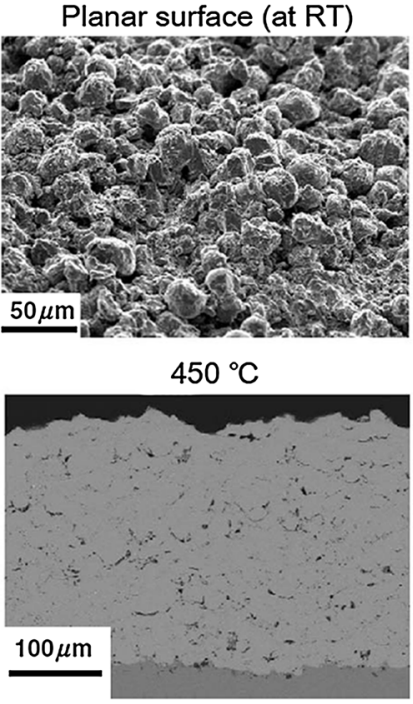

(a)

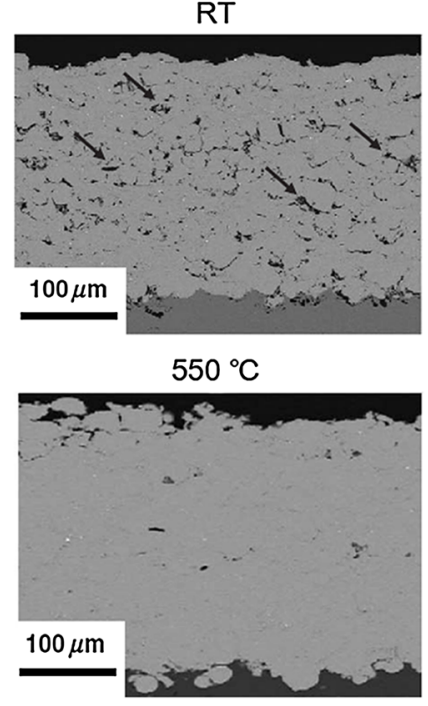

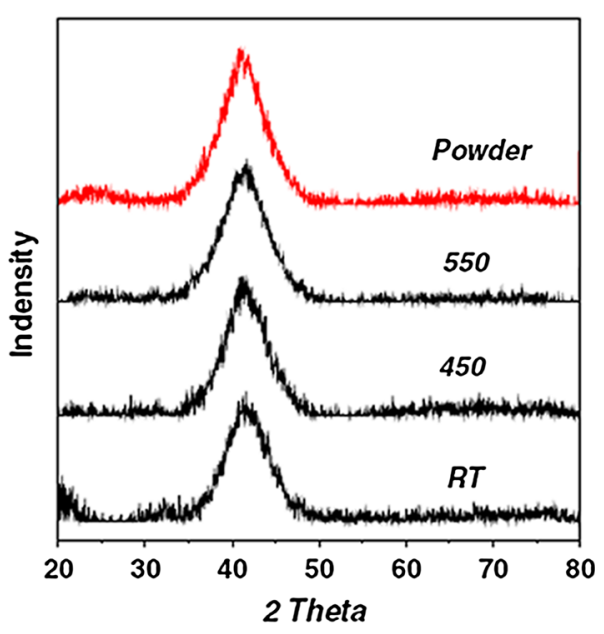

(b)

Fig. 2 (a) NiTiZrSiSn coating layer deposited via kinetic spray under various process conditions (no pre-heating, pre-heating at 450 and $500{ }^{\circ} \mathrm{C}$ ), and (b) XRD diffraction peaks of the NiTiZrSiSn amorphous alloy feedstock material and as-sprayed coatings in accordance with the powder pre-heating temperature $\left(450\right.$ and $\left.500{ }^{\circ} \mathrm{C}\right)$

In Fig. 2(a), the deposit grew increasingly dense with the increase in powder pre-heating temperature, since the plastic deformation resistance of impacting particles was reduced as a result of pre-heating. However, according to the result of XRD diffraction analysis of NiTiZrSiSn coating layer (Fig. 2b), no phase transformation occurred in the deposited coating layer, even with the pre-heating of particles during the process. This result implies that the heat energy provided from the pre-heating chamber only softened the impacting particles and did not cause any phase transformation.

As demonstrated by Assadi et al., the high-velocity (above the critical velocity of each material) impact of particles induces an instantaneous rise in temperature, and takes place in the vicinity of the interface, particularly at the periphery of the interface (Ref 9). In accordance with the results of particle impact modeling, the maximum temperature can rise momentarily to $0.99 \mathrm{~T}_{\mathrm{m}}$. Consequently, a small phase transformation (amorphization and crystallization) or chemical reaction (formation of intermetallic compounds) can be developed. For example, according to Xiong et al., some parts of the interface region in the pure $\mathrm{Al}$ deposit produced via kinetic spray showed amorphous structures. Figure 3 presents TEM images of individual $\mathrm{Al}$ particle impact at the interface between the Al particles and the substrate (Ref 63).

In Fig. 3(b), a well-bonded interface was observed with some flow-like areas $(\sim 10 \mathrm{~nm})$. The boxed area in Fig. 3(b) was measured under high magnification (Fig. 3c) for additional investigation, and, as a result of the diffraction pattern analysis, the creation of a $\sim 3-\mathrm{nm}$ thickness of this amorphous Al layer was confirmed. The primary causes of such amorphization at the vicinity of the interface region are the high-strain/strain-rate deformation with shear instability and the heat generation to $0.99 \mathrm{~T}_{\mathrm{m}}$ followed by rapid quenching.
On the other hand, in the case of amorphous materials, the crystallization can be generated near the interface region the kinetic sprayed amorphous material. S. Yoon et al. researched the strain-enhanced nanocrystallization at the interface area of the CuNiTiZr coating formed by kinetic spray. Figure 4 shows the HREM image of the nanocrystalline region in the CuNiTiZr coating (Ref 64).

The crystallized area appeared at the periphery of the particle-particle interface of CuNiTiZr BMG deposit, as demonstrated in Fig. 4. Similar to the amorphization of pure $\mathrm{Al}$, a high degree of plastic strain and intense heat generation induced the crystallization of CuNiTiZr by decreasing the activation energy for the crystallization. Here, the amount of crystallization increased with the gas pressure (from 1.5 to $3.0 \mathrm{MPa}$ ) due to the greater energy supply under the higher process gas pressure.

In addition, some intermetallic compounds can be formed occasionally at the limited area near the interface between deposited particles. In the research of Guetta, which investigated the effect of particle velocity on the bonding of impacting particles, the creation of $\mathrm{Al}-\mathrm{Cu}$ intermetallic compounds was confirmed by TEM images and FFT pattern analysis, as shown in Fig. 5 (Ref 65).

The intermetallic compounds $\mathrm{Al}_{4} \mathrm{Cu}_{9}$ and $\mathrm{Al}_{2} \mathrm{Cu}$ are approximately $\sim 400 \mathrm{~nm}$ in size, and were created between deposited $\mathrm{Al}$ particles and the $\mathrm{Cu}$ substrate. These $\mathrm{Al}-\mathrm{Cu}$ intermetallic compounds were the result of a high degree of heat generation with adiabatic shear instability, which reinforced the atomic diffusion and chemical reaction between $\mathrm{Al}$ and $\mathrm{Cu}$ elements.

In summary, phase transformations and the formations of intermetallic compounds hardly occur due to highly localized plastic deformation and thermal energy generation, when a kinetic-sprayed deposit is examined overall with a macroscopic scale. However, very small phase 

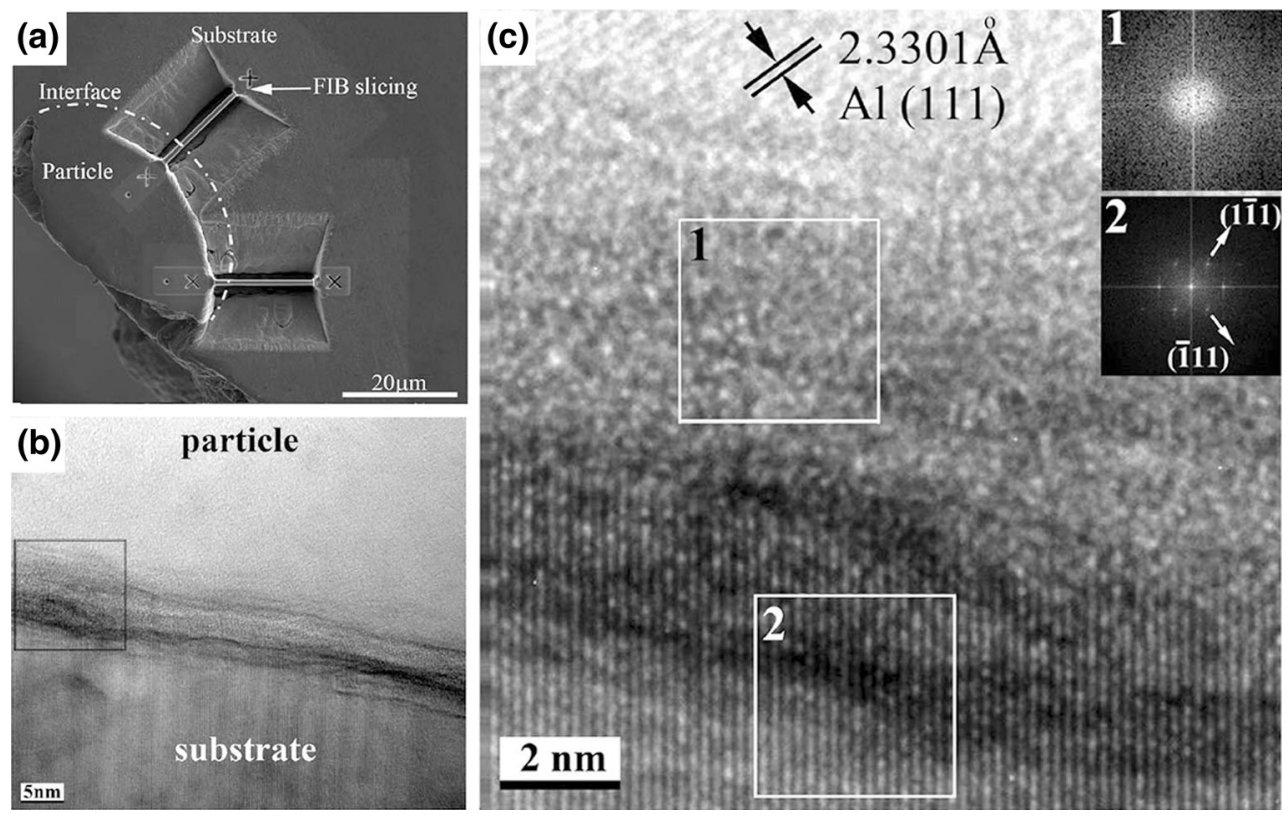

Fig. 3 TEM images of the individual Al particle impact interface between Al particles and the substrate: (a) sample preparation via FIB, (b) HREM images of the individual Al particle impact interface between Al particles and the substrate, and (c) high-magnification images of the boxed region in (b) and FFT (Interpret Fourier Transforms) patterns of selected area

transformations (i.e., amorphization and crystallization) or chemical reactions (i.e., creation of intermetallic compounds) can be generated near the particle-particle and particle-substrate interface area.

\subsection{Heat Treated Specimens}

Kinetic-sprayed specimens contain residual stress in the coating layer following the deposition process. Chemical/ metallurgical bonding is achieved only at the periphery of the particle-particle and particle-substrate interface. The majority of the interface is restrained by mechanical interlocking, induced by severe plastic deformation of impacted particles involving jetting at the periphery of interface. Therefore, kinetic-sprayed specimens are typically heat treated to release the residual stress and to derive the additional chemical/metallurgical bonding at the interface, which enhances the mechanical properties.

However, heat treatment is also applied to produce new phases by phase transformation or chemical reaction at the interface between the particle-particle and the particle-substrate. Such formations of new phases are attributed to the externally supplied thermal energy during heat treatment. In phase transformation, as with the bulk alloy, new phases can be obtained by heating the specimen above the phase transformation temperature for a period of time (Ref 83).

Additionally, intermetallic compounds can be created at the interface region via chemical reaction between the components of deposited materials. In the intermetallic compound formation procedure, the control of the heat treatment temperature plays a key role. The diffusion of elements in the kinetic-sprayed specimen becomes more active in accordance with the rise of heat treatment temperature, which contributes to the successive formation of intermetallic compounds beyond the vicinity of the interface region. At this point, the quantity of intermetallic compounds grows along with the increase in temperature due to the extended diffusion length which is associated with the higher heat treatment temperature. Yang et al. conducted an investigation about the microstructure and the erosion performance of post-heat treated $\mathrm{Fe}-\mathrm{Al}$ coating layers deposited via the kinetic spray (Ref 68). According to this research, increasing quantity of $\mathrm{FeAl}$ intermetallic compounds was created along with the increase in heat treatment temperature. Cross-sectional SEM images of assprayed and heat treated deposits are presented in Fig. 6.

The white areas in Fig. 6(a) represent the Fe-rich phase, and the gray lamella areas were Al-rich $\mathrm{Fe}-\mathrm{Al}$ solid solution. This microstructure was maintained following kinetic spray deposition, as shown in Fig. 6(b). Remarkably, after heat treatment of the kinetic-sprayed Fe-Al deposit, the white Fe-rich region and Al-rich lamella structure disappeared and $\mathrm{FeAl}$ intermetallic compounds were created. As mentioned above, the quantity of $\mathrm{FeAl}$ intermetallic compounds increased in accordance with the increase in heat treatment temperature (Fig. $6 \mathrm{c}$ and d). The dark gray particles in 6(d) appearing after heat treatment were Al-rich oxides based on the pre-existing oxide particles in the as-sprayed deposit.

Various distinctive kinds of intermetallic compounds can be formed based on the heat treatment temperature due to the difference in required chemical reaction temperatures between the intermetallic compounds. For example, each of four types of intermetallic compounds in 

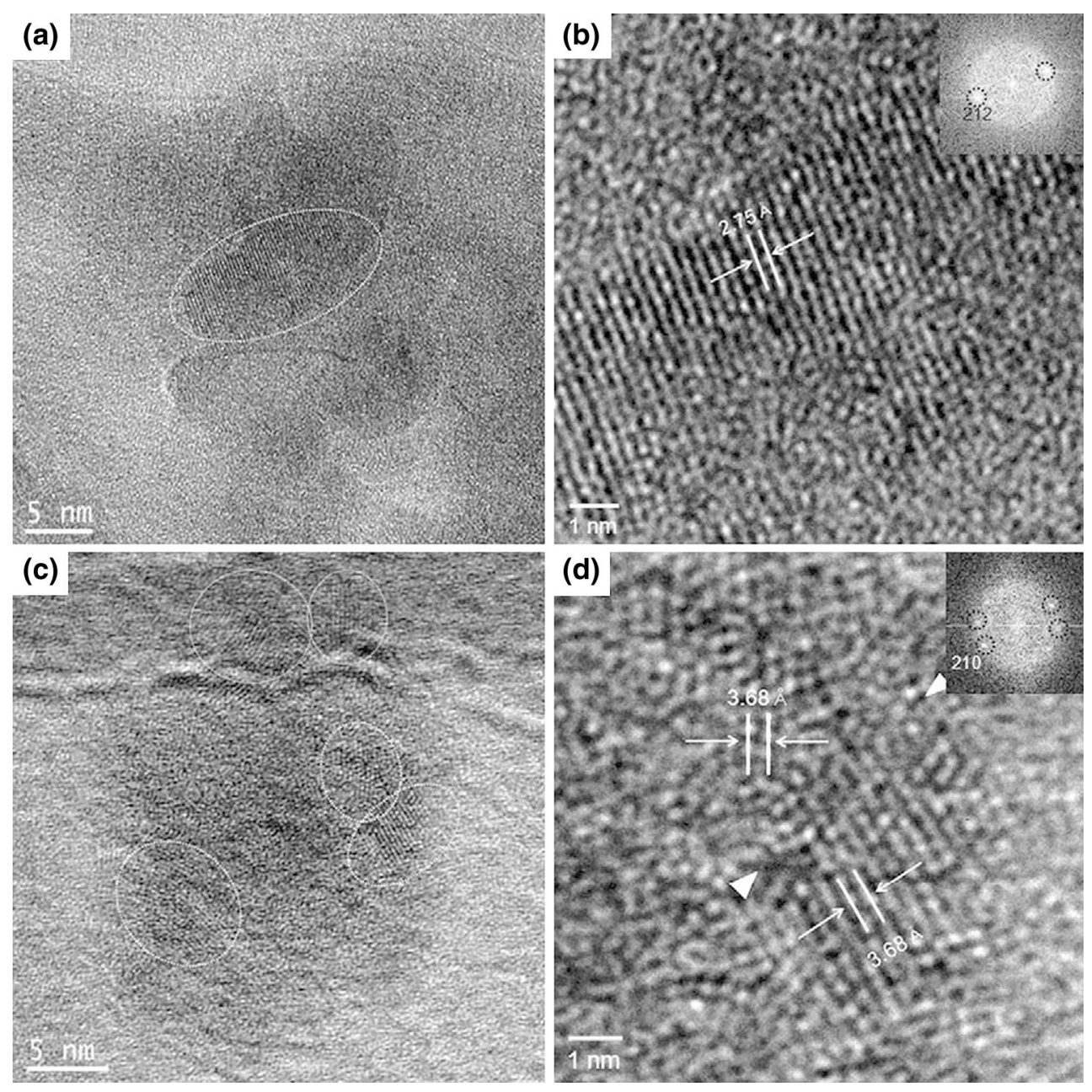

Fig. 4 HREM images of the crystalline area in the CuNiTiZr coating deposited via kinetic spray: (a) HREM image of nanosized crystals in the $\mathrm{Cu}$-based BMG coating deposited under a pressure of $1.5 \mathrm{MPa}$; (b) high-magnification HREM image and FFT pattern in selected area of (a), (c) HREM image of nanosized crystals in the Cu-based BMG coating deposited under a pressure of $3.0 \mathrm{MPa}$; and (d) highmagnification HREM image and FFT pattern in selected area of (c)

the Ti-Al metal composites (i.e., $\mathrm{TiAl}_{3}, \mathrm{TiAl}_{2}$, $\mathrm{TiAl}$, and $\mathrm{Ti}_{3} \mathrm{Al}$ ) has a distinct temperature which is required for creation. Thus, for the kinetic-sprayed Ti-Al composite coating layer, it is possible that distinct types of Ti-Al intermetallic compounds are formed with regard to the heat treatment temperature. Figure 7 shows cross-sectional BSE images of the post-heat treated Ti-Al coating layer captured by FE-SEM (Ref 74).

However, the heat treatment temperature and time should be carefully adjusted to prevent the delamination between the components of the kinetic-sprayed specimen, which is caused by differences in the thermal expansion coefficient.

\section{Inhomogeneity of the Kinetic-Sprayed Coating}

Most of the high-strain/strain-rate plastic deformation in the kinetic spray process is concentrated in the neighborhood very close to the interface. Therefore, the region near the interface of the deposited particle presents a microstructure different from that of the inner part of particle, where the microstructure is similar to that of the as-received material. This is clearly suggested in the research of King et al., which examined the refinement of grains in kinetic-sprayed copper particles. Figure 8 presents the microstructure of single kineticsprayed $\mathrm{Cu}$ particle on the $\mathrm{C}-11000 \mathrm{Cu}$ substrate (Ref 52).

In Fig. 8(b), the interior of the deposited $\mathrm{Cu}$ particles was divided into the four parts, from the inner region to the interface region, in sequence from A to D. The degree of plastic deformation of the grains clearly intensified in the order of $\mathrm{A}, \mathrm{B}, \mathrm{C}$, and $\mathrm{D}$. That is, the morphology of grains in the inner particle area (A and $\mathrm{B}$ ) was similar to that of the feedstock $\mathrm{Cu}$ powder (Fig. 8a), while the grains near the interface region ( $\mathrm{C}$ and $\mathrm{D})$ were highly deformed and elongated due to the concentrated high-strain/strainrate plastic deformation. 


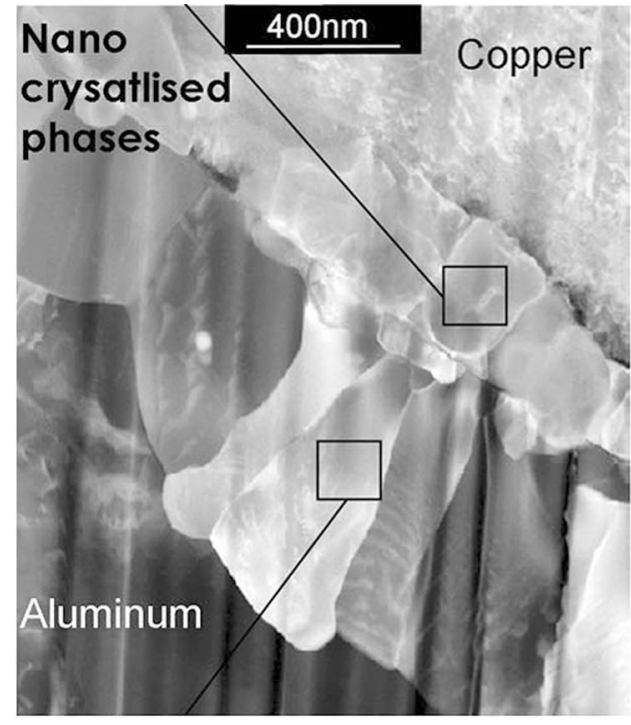

(a)
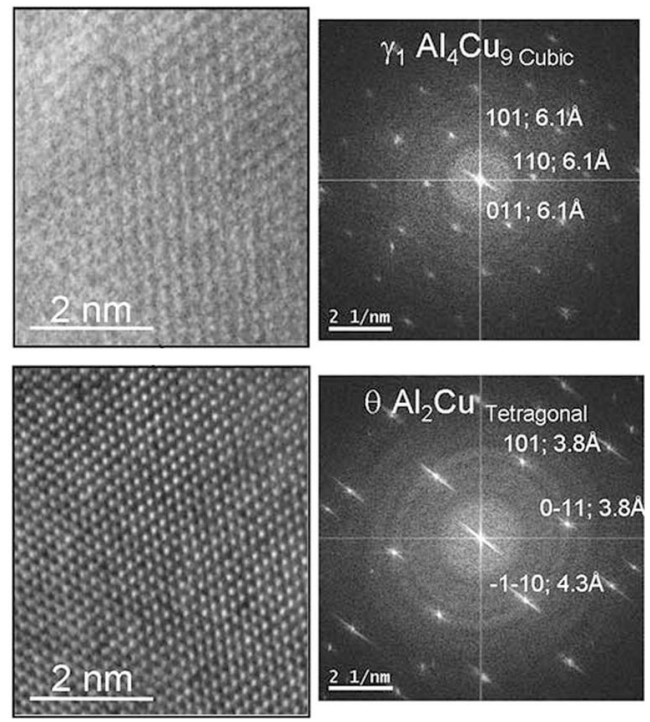

(b)

Fig. 5 TEM images and FFT pattern analysis of Al-Cu intermetallic compounds at the interface region: (a) TEM image of the interface region with the Al-Cu intermetallic compounds, and (b) high-magnification HREM images and FFT pattern analysis of each intermetallic compound for the boxed area in (a)
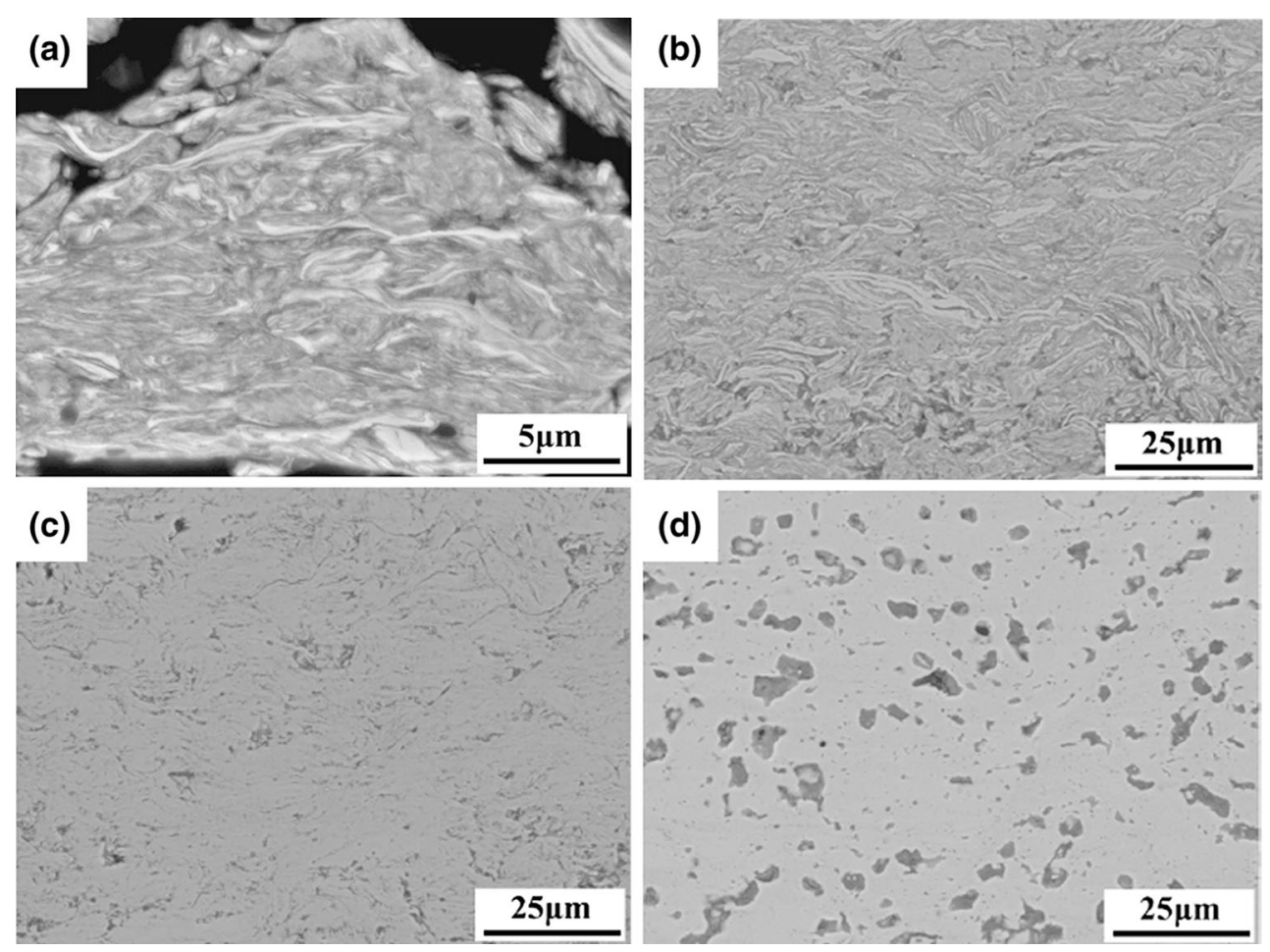

Fig. 6 Cross-sectional SEM images: (a) Ball-milled Fe-Al feedstock powder, (b) as-sprayed Fe-Al deposit, (c) heat treated Fe-Al deposit at $650{ }^{\circ} \mathrm{C}$, and (d) heat treated $\mathrm{Fe}-\mathrm{Al}$ deposit at $950{ }^{\circ} \mathrm{C}$

In particular, adiabatic shear instability is generated at the periphery of the interface and results in susceptibility of the edges of the particle-particle and particle-substrate interface to plastic shear deformation. Consequently, a highly localized deformed structure is created at the interface region of the deposited particles with the for- mation of jets. The jetting can be easily found when the deposited single particle is observed by SEM. Figure 9(a) clearly shows a kinetic-sprayed single $\mathrm{Cu}$ particle. It is very obvious that the jetting is created around the deposited $\mathrm{Cu}$ particle, which is the result of the research of Assadi et al. (Ref 9). 

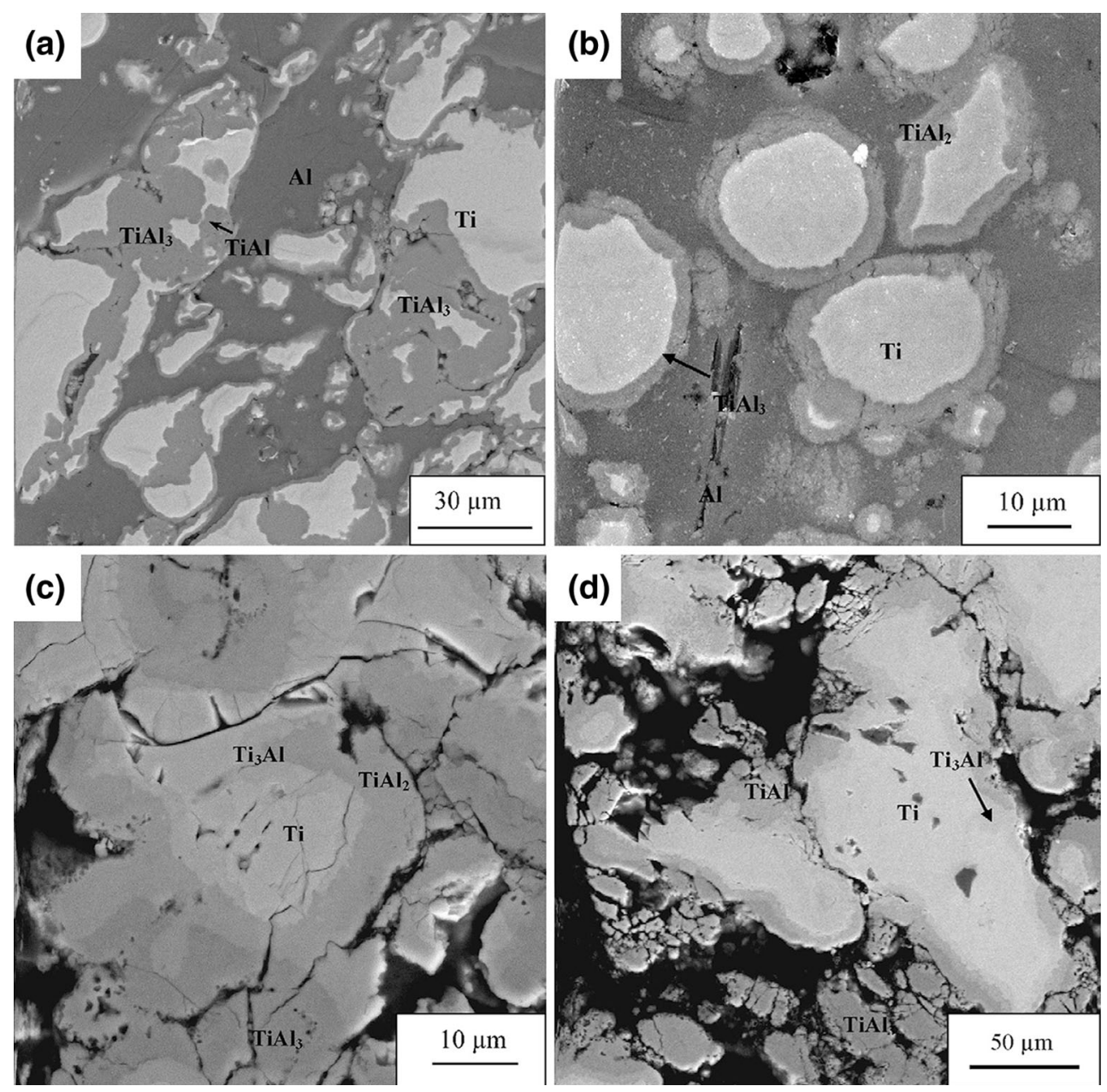

Fig. 7 The cross-sectional BSE images of kinetic-sprayed Ti-Al deposit after the heat treatment: (a) annealed at $650{ }^{\circ} \mathrm{C}$ for $3 \mathrm{~h}$, (b) annealed at $650{ }^{\circ} \mathrm{C}$ for $16 \mathrm{~h}$, (c) annealed at $650{ }^{\circ} \mathrm{C}$ for $6 \mathrm{~h}$ and following holding at $850{ }^{\circ} \mathrm{C}$ for $3 \mathrm{~h}$, and (d) annealed at $650{ }^{\circ} \mathrm{C}$ for $16 \mathrm{~h}$ and following holding at $850^{\circ} \mathrm{C}$ for $3 \mathrm{~h}$
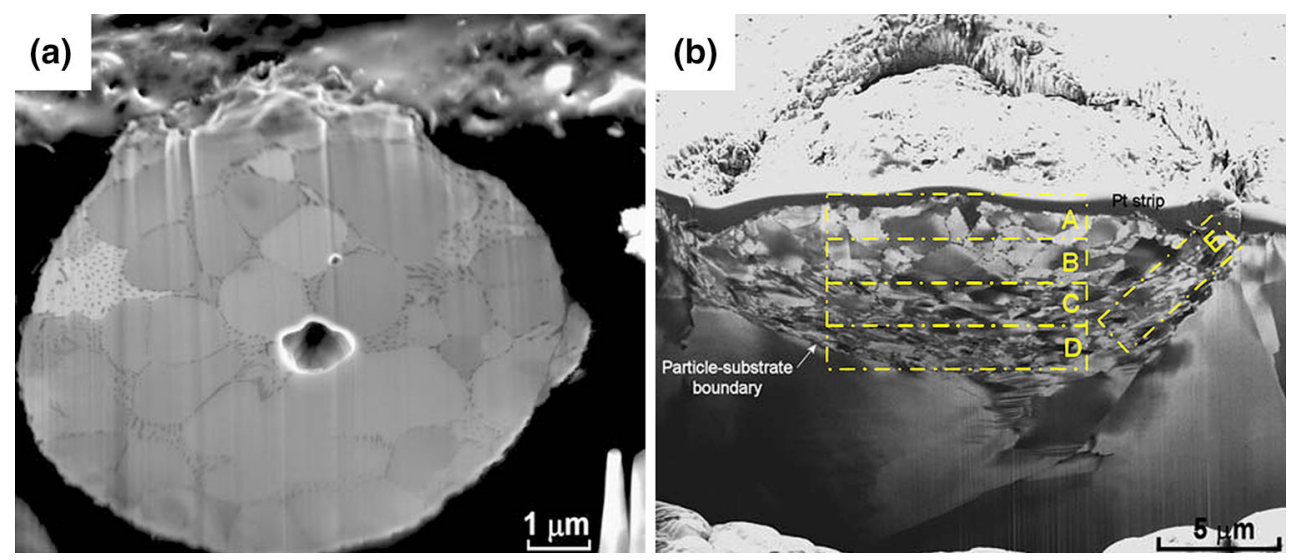

Fig. 8 The observed microstructure of the cross section: (a) feedstock $\mathrm{Cu}$ particle and (b) single kinetic-sprayed Cu particle

However, jetting cannot easily be detected in the case of multi-particle deposition, due to the high degree of additional plastic deformation caused by subsequent impacting particles and the crumbling of jetting morphology. One method of distinguishing jetting is to find the 'folded' structure, which is marked with a solid black arrow in Fig. 9(b) (Ref 53).

Furthermore, tangled, mixed structure can be generated in a local area by the generation of transient interfacial instability at the moment of impact. According to 

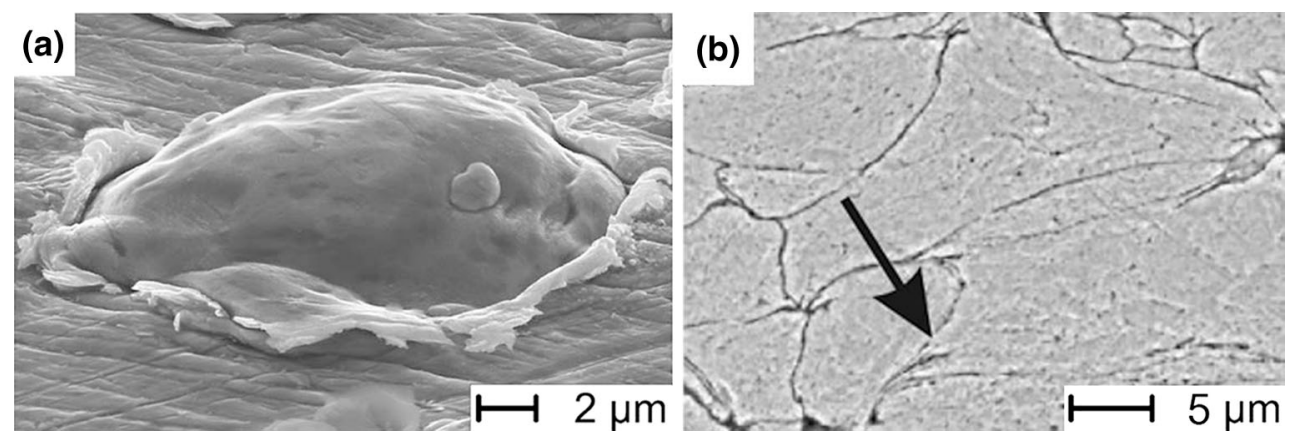

Fig. 9 (a) The SEM images of kinetic-sprayed Cu: (a) a single particle and (b) a cross section of multi-particle deposit

the research of Grujicic et al., the most reliable cause of transient interfacial instability is the Kelvin-Helmholtz instability phenomenon (Ref 84). Kelvin-Helmholtz instability can occur when two contacting fluids move in parallel to their interface at different velocities. As a result, interfacial roll-ups and vortices can be formed since the appearance of interface perturbation was followed by centrifugal force. In the case of kinetic-sprayed deposits, this phenomenon can be caused by the viscous flow at the interface during the impact stage, particularly at the periphery of the interface. Practical examples of tangled and mixed structures with interfacial roll-ups and vortices are well described by L. Ajdelsztajn et al. (Ref 49). Figure 10(a) shows a mixed structure induced at the interface between deposited $\mathrm{Ni}$ particle and the Al substrate. The roll-ups and vortices can be clearly observed within the range of a few microns. The tangled structure can be generated on a significantly smaller scale (a few hundred nm), as shown in region 'A' of Fig. 10(b) (Ref 54).

At this point, it is important to note that these kinds of tangled and mixed structures contribute to enhance the bonding between particle-particle and particle-substrate, by induced mechanical interlocking. Referentially, the mechanical bonding created by the mechanical interlocking dominates the bonding formed in the deposit, while the chemical/metallurgical bonding via adiabatic shear instability occupies only a small portion restricted to the periphery of the interface.

Above this, microscopically, additional microstructural changes appear during the deposition at the interface region due to heat generation up to $0.99 \mathrm{~T}_{\mathrm{m}}$ and a high degree of plastic deformation. Dynamic or SRV/recrystallization, grain refinement, dislocation loops or shear bands generation, and twin formation can be produced at the interface region in accordance with the process conditions and material properties which yield distinction in particle impact behavior. A more detailed explanation is presented in section 5 (Microstructure of Kinetic-Sprayed Coatings).

\section{Density, Pores, and Micro-cracks}

In terms of producing a deposit on the substrate, it is in general preferable to acquire high-density and low-porosity coating layers without any defects. The coating layers deposited via kinetic spray process exhibit a significantly higher density and lower porosity than the thermal-sprayed deposits. Since the particles deposited by kinetic spray process experience severe plastic deformation, the empty space between the impacting particles is filled up by the flow of highly deformed particles. The subsequent particle impact induces a compaction of predeposited particles in the coating layer, which is referred to as the tamping effect. This effect can be clearly observed in Fig. 11, which is the result of pure Ti deposition using the kinetic spray process (Ref 36).

Figure 11(a) shows the bulk-scale Ti deposit produced by kinetic spray process. During the deposition stage, previously deposited $\mathrm{Ti}$ particles were tamped by subsequent particle impact due to sufficiently high hardness of Ti particles. Thus, the microstructure became denser and denser from the upper part of the deposit (Fig. 11b) to the lower part of the deposit (Fig. 11d).

However, due to high-pressure generation at the moment of impact, a shock wave spreads out from the point of collision into the inner particle and, consequently, micro-cracks can be initiated at some defects. Such microcracks are usually observed at the particle-particle interface as perfect chemical or metallurgical bonding cannot be obtained throughout the entire coating layer. The requirements for the formation of chemical/metallurgical bonding are primarily achieved at the periphery of the interface, where the instantaneous peak temperature can be $0.99 \mathrm{~T}_{\mathrm{m}}$ at the moment of impact. Figure 12 clearly shows the difference in the bonding state along the interface between the deposited particle and the substrate (Ref 85).

It can be readily determined from the undistinguishable particle-substrate boundary that the edge regions of the interface were well bonded, which was a result of the generation of adiabatic shear instability and heat energy. A narrow gap existed between the deposited $\mathrm{Ni}$ particle and $\mathrm{Cu}$ substrate at the center of the interface. As is well known in the kinetic spray field, two factors contribute to the failure of successful bonding formation: strong springback force due to the elastic rebound energy, and insufficient bonding energy. As a result, micro-cracks often appear at the center of the interface. In the case of metalceramic composite, micro-cracks can be generated at the 

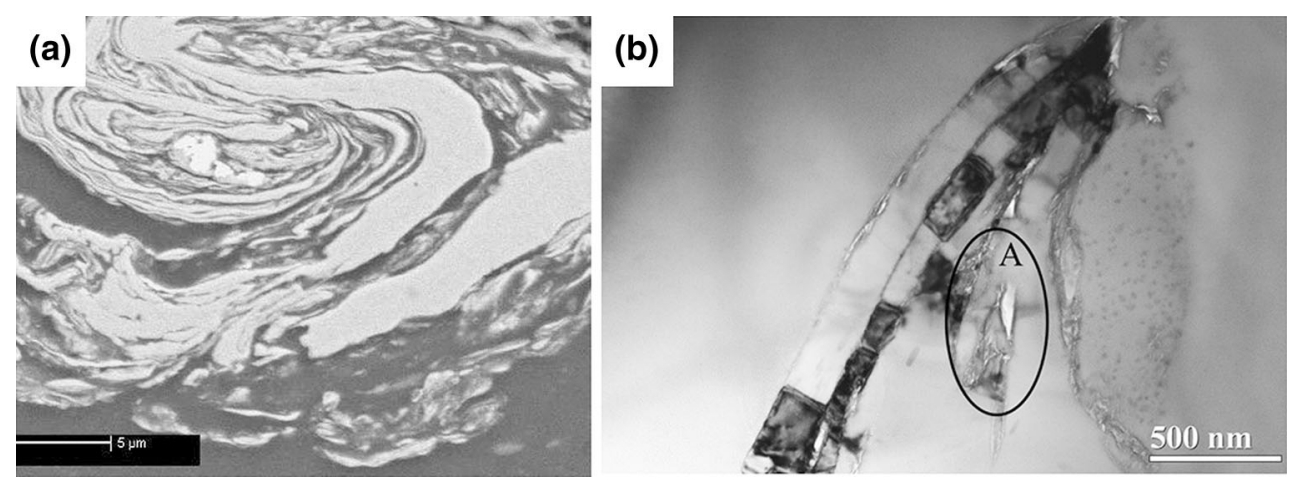

Fig. 10 (a) Backscattered SEM image of interfacial roll-ups and vortices in kinetic-sprayed Ni deposit on the Al substrate and (b) TEM image of the kinetic-sprayed $\mathrm{Al}$ particle boundary
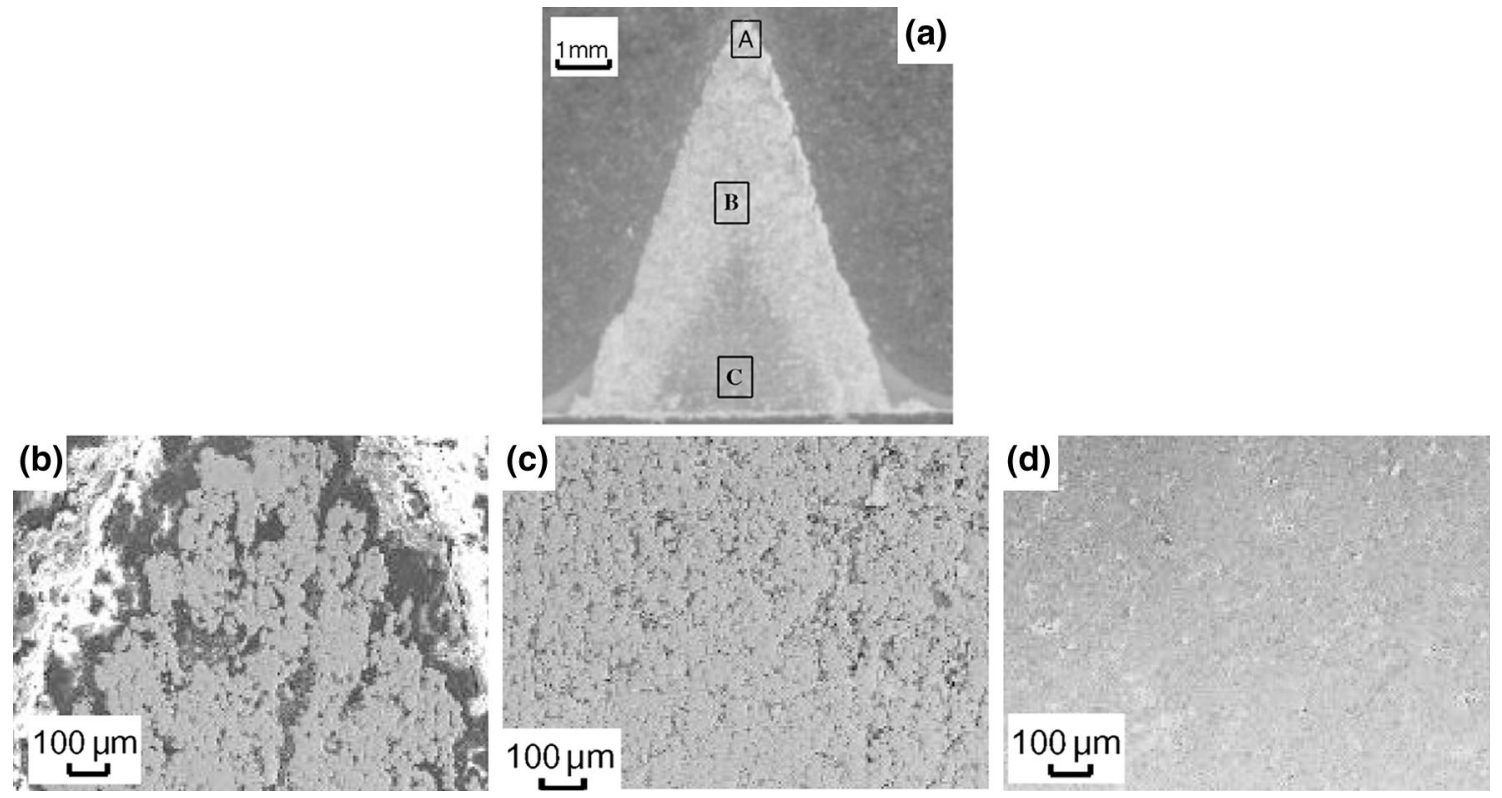

Fig. 11 Microstructures of kinetic sprayed Ti deposit: (a) Entire cross-sectional image of the Ti deposit, (b) magnified image of the region marked $\mathrm{A}$ in (a), (c) magnified image of the region marked $\mathrm{B}$ in (a), and (d) magnified image of the region marked $\mathrm{C}$ in (a)

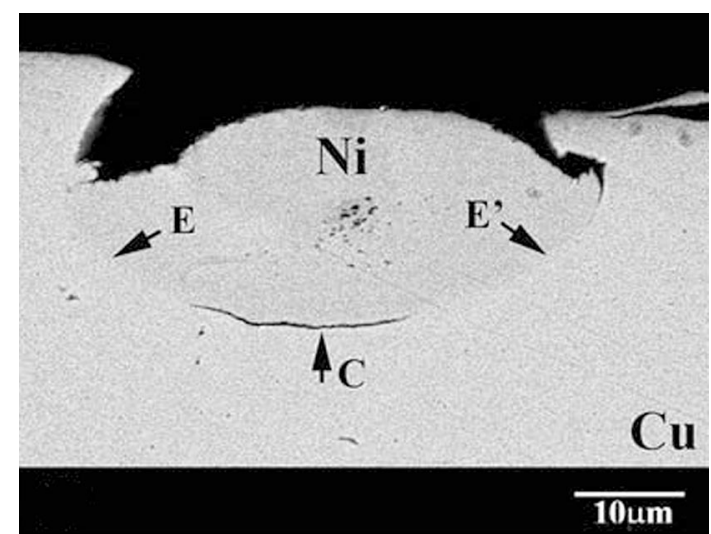

Fig. 12 Cross-sectional SEM images of kinetic-sprayed Ni particle on the $\mathrm{Cu}$ substrate; the edges of the interface are marked as $\mathrm{E}$ and the center area of the interface is marked as $\mathrm{C}$ time of impact between ceramic portions. Since the particles should be plastically deformed to create the bonding, the impact between brittle ceramic portions of particles causes micro-cracks at the interface or inner particle due to the lack of plasticity.

These micro-cracks degrade the mechanical properties of the coating layer such as ductility and adhesive/cohesive bond strength. Thus, to reduce the micro-cracks, it is much better to heat treat the kinetic-sprayed coating layer after the deposition step. Also, the pores in the deposit can be additionally decreased by heat treatment due to the diffusion. Figure 13 presents the effect of heat treatment on the porosity of kinetic-sprayed $\mathrm{Cu}$ deposit, which is the result of $\mathrm{Li}$ et al. (Ref 69). In this case, the pure $\mathrm{Cu}$ was deposited and post-heat treated to observe the microstructural change resulting from the heat treatment. The porosity of the $\mathrm{Cu}$ deposit was significantly reduced after post-heat treatment and the degree of porosity reduction 
increased with heat treatment time (Ref 69). In addition to decreased porosity, other microstructural altering phenomena can be induced by heat treatment. A more detailed discussion is presented in section 5 .

\section{Microstructure of Kinetic-Sprayed Coatings}

From a macroscopic point of view, a highly dense coating layer is created by filling the empty space between deposited particles that results from the high degree of plastic deformation of impacting particles as a result of the tamping effect. The inner part of the deposited particles exhibits a microstructure similar to that of the as-received powder, since the influence range of severe localized plastic deformation and heat generation is highly limited to the vicinity of the interface region. From a microscopic point of view, localized severely deformed layers and tangled/mixed structures are induced by adiabatic shear instability at the periphery of the particle interface. The generated heat energy in particular, which manifests in temperature peaks of $0.99 \mathrm{~T}_{\mathrm{m}}$ in the periphery region of the interface, produces some microstructural transitions such as grain refinement, dynamic or SRV/recrystallization, dislocation loops or shear bands generation, and twin formation.

\subsection{As-Sprayed Specimens}

Deformed material structures such as dislocations and shear bands are the outcome of energy conversion from mechanical force (shear force on materials) to strain energy, appearing in the form of defects. Accordingly, it can be said that deformed materials are thermodynamically unstable and thus move toward stable states when conditions allow.

In the case of the aforementioned kinetic-sprayed specimens, highly distorted and deformed layers are created near the interface region due to the high-velocity impact of deposited particles. At the same time, temperature can increase up to $0.99 \mathrm{~T}_{\mathrm{m}}$ at the periphery of the interface region due to the development of adiabatic shear instability. As a result, some microstructural changes (grain refinement and static or DRV/recrystallization) are produced near the particle-particle or particle-substrate interface in the sequence of relieving strain energy assisted by thermal energy generated from high-pressure impact with adiabatic shear instability.

As mentioned above, the high-pressure impact of particles generates a number of dislocations near the interface region. In this process, the localized high dislocation density can produce a number of dislocation cells, which typically become subgrains. Accordingly, grains in the vicinity of the interface region are somewhat refined relative to the grains in the inner region of the deposited particles. This type of grain refinement sequence is described in Fig. 14, which is suggested in the study of Zou et al. (Ref 57).
It is well known that, when an extremely high dislocation density is created during deformation, dislocations are not randomly generated in the deformed region, but are instead gradually arranged in the form of dislocation cells. In the case of severely deformed kinetic-sprayed particles, it is reasonable to assume that some elongated subgrains are formed near the grain boundaries, which is the result of high accumulated dislocation density. The elongated shape of subgrains is a result of simultaneous plastic deformation at the moment of the subgrain formation (Ref 57).

In addition to simple grain refinement resulting from the formation of elongated subgrains, recovery or recrystallization can also occur concurrently with plastic deformation of impacting particles during the particle impact stage. These types of recovery and recrystallizations are referred to as DRV and DRX. In DRV, the stored strain energy is reduced by the annihilation of dislocation dipoles, which is actuated by interactions between stored network dislocations and mobile dislocations at elevated temperatures; a dislocation dipole means the two dislocations of opposite signs on different slip planes, which are separated by an atomic scale distance. More specifically, the annihilation of dislocation dipoles results from the non-zero force components perpendicular to the slip planes due to the elastic interaction between dipoles. At this point, the corresponding motion of the dislocations out of the slip plane to the elastic force is only possible via dislocation climb, which is extremely active at elevated temperatures (Ref 86-89). In the case of kinetic-sprayed particles, the build-up of high dislocation density and heat energy near the interface region satisfies the requirements for the elimination of dislocation dipoles by dislocation climb and, accordingly, DRV occurs in the vicinity of the interface region.

On the other hand, the relief of stored energy in DRX is caused by the formation of new dislocation-free grains. Two mechanisms form the basis of this process: migrational DRX and rotational DRX. Migrational DRX involves the migration of high-angle grain boundaries into the highly strained region and, as a result, new strain-free grains are formed to reduce the stored energy. However, in kinetic-sprayed specimens, the DRX phenomenon near the interface of the deposited particles cannot be explained with the migrational DRX mechanism due to significantly low high-angle grain boundary mobility under a fairly high strain rate, which exceeds $4.0 \times 10^{4} \mathrm{~s}^{-1}$ (Ref 90). The rotational DRX mechanism is a likely cause of DRX adjacent to the interface region. In the case of rotational DRX, strain-free grains are created in another way. A detailed sequence of rotational DRX is shown in Fig. 15, which is also described in the research of Zou et al. (Ref 57).

As mentioned above, some elongated dislocation cells and subgrains can be formed at the vicinity of the interface region during the particle deposition stage (Fig. 15a). When the deformation of impacting particles continues even after the creation of elongated subgrains, those elongated subgrains are broken into smaller pieces (Fig. 15b). Consequently, broken subgrains are rotated by additional shear 

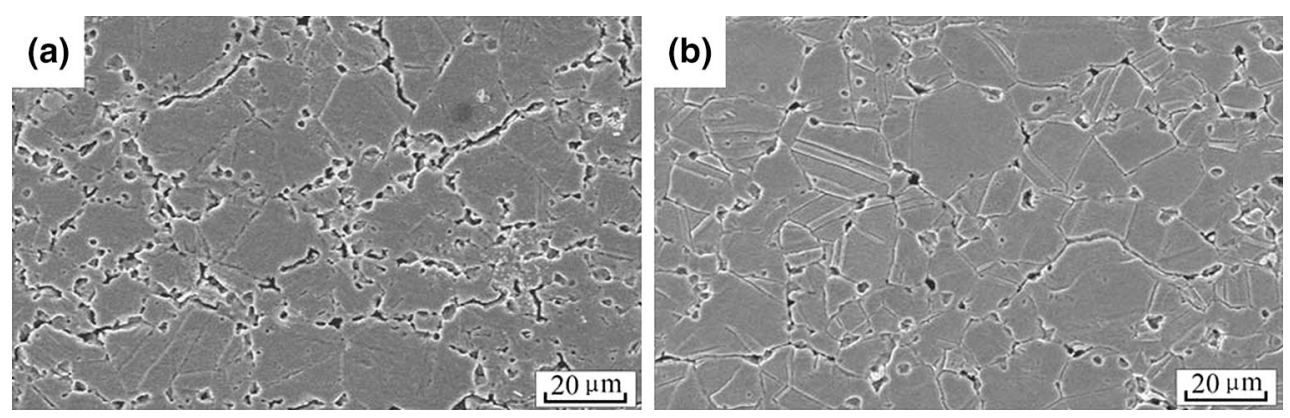

Fig. 13 The cross-sectional SEM images of kinetic-sprayed and post-heat treated $\mathrm{Cu}$ coating layer at $600{ }^{\circ} \mathrm{C}$ for a certain time: (a) $1 \mathrm{~h}$, (b) $12 \mathrm{~h}$

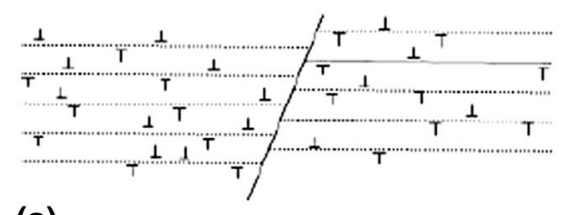

(a)

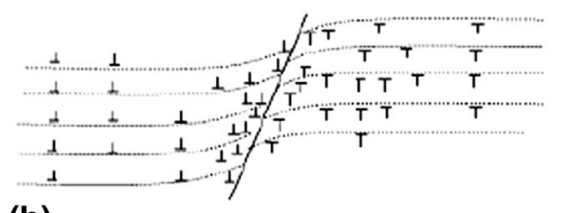

(b)

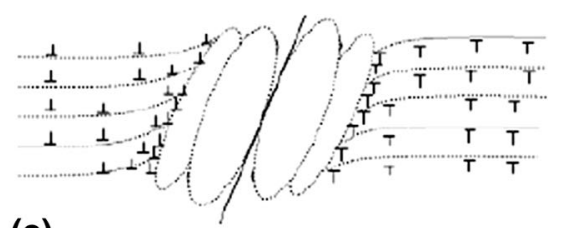

(c)

Fig. 14 The sequence of subgrain formation induced by the high level of accumulated dislocation: (a) non-deformed microstructure with low dislocation density before the deposition stage, (b) accumulation of dislocations with the shear between lattices during impact, and (c) grain refinement resulting from the formation of elongated subgrains

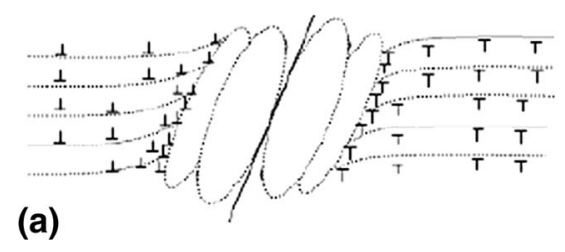

Fig. 15 A sequence of rotational DRX: (a) formation of elongated subgrains due to an accumulation of dislocations, (b) break-up of elongated subgrains, and (c) the rotation of the broken subgrains

forces and refined strain-free grains are finally formed (Fig. 15c). Figure 16 presents the EBSD characterization of the microstructure of kinetic-sprayed Ni particles adjacent to the interface region, as induced by DRX (Ref 57).

As shown in Fig. 16(a), the grains near the particleparticle interface were highly refined due to the DRX phenomenon. Although refined grains can result from SRV or SRX, DRX is a more reasonable cause of the refined grains in this case, since the pattern quality of the refined grains was significantly lower than that of the coarse inner particle grains. In contrast to the strain/defect-free grains created by SRX, the newly formed grains via DRX still contain dislocations due to the simultaneous plastic deformation even during the process of DRX (Fig. 16b). Subsequently, the degree of grain misorientation increased from point $\mathrm{A}$ (inner particle) to point $\mathrm{D}$, as a result of new refined grain creation by DRX.

SRV and SRX can occur by an assistance of the residual heat during the cooling process following the plastic deformation stage of impacted particles, if sufficient heat energy to induce SRV or SRX is maintained for a certain times. Especially, in the case of high-adiabacity materials like titanium, SRV and SRX can be much more developed due to higher persistency of thermal energy and this was investigated by G. Bae et al. in 2010 (Ref 56). Here, the adiabacity means the ability of material to keep thermal energy in limited part. Figure 17 shows a high-magnification TEM image of the kinetic-sprayed titanium interface region, where the particle-particle interface is marked with white arrows. A distribution of dislocation-free nanograins can clearly be observed along the interface, caused by grain refinement through DRV and DRX, and dislocation annealing through SRV. The refined nanograins were produced via DRV and DRX. Subsequently, the remaining nanograin dislocations were removed by SRV, which was driven by the residual heat present as a result of the low thermal conductivity of $\mathrm{Ti}$ (high adiabacity) (Ref 56).

These SRV and SRX can be enhanced by additional heating caused by the tamping effect from subsequent particle impacts. On the basis of this principle, SRV and SRX can be induced even in the presence of high thermal conductivity (low adiabacity) materials such as $\mathrm{Al}$ and $\mathrm{Cu}$. This implies that the duration of heat energy induced by the subsequent particle impact is sufficient to generate 

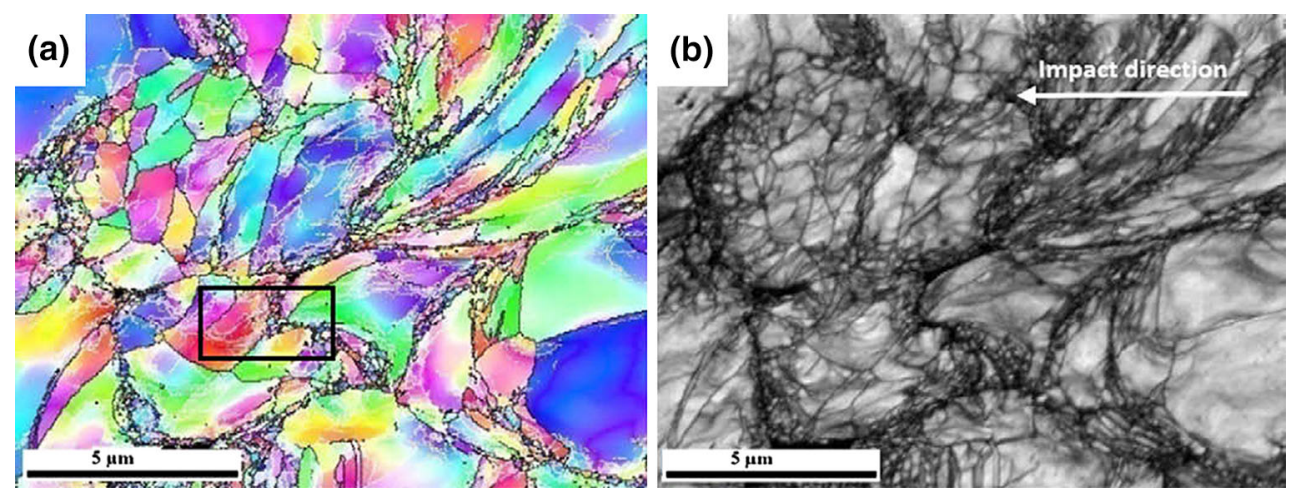

Fig. 16 EBSD characterization of the as-sprayed Ni coating: (a) Euler angle map, and (b) pattern quality map

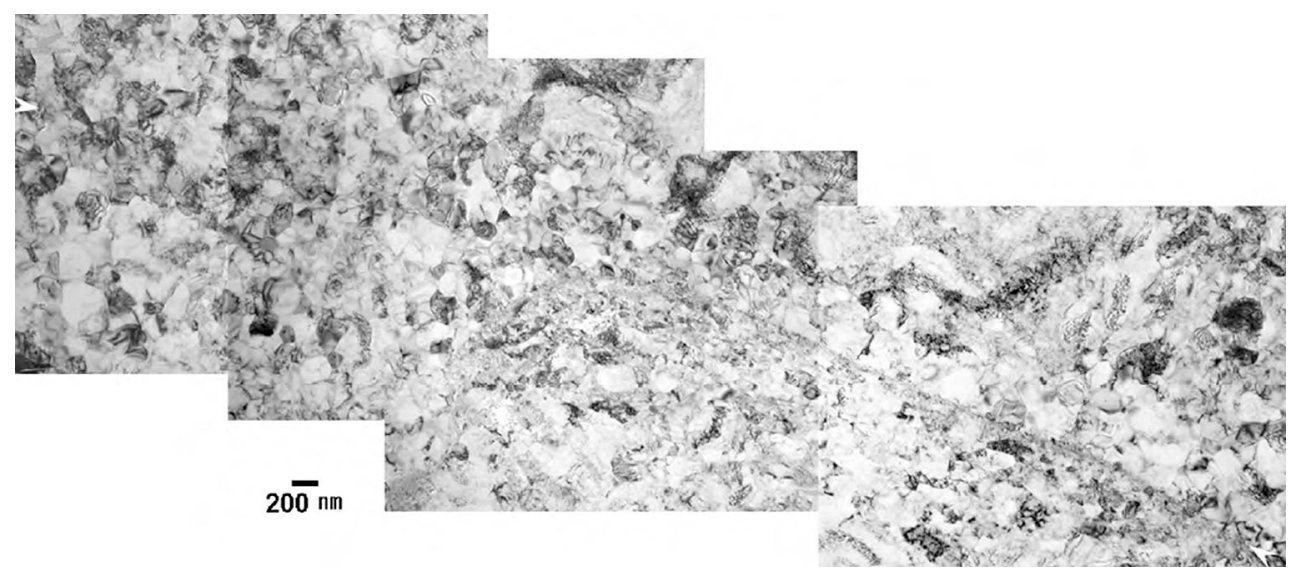

Fig. 17 A high-magnification TEM image of particle-particle interface region in kinetic-sprayed Ti

SRV and SRX, though the actual duration is extremely short and the influence range of subsequent particle impact is limited to just a few layers on the basis of impact location. The sequence of SRV and SRX affected by successive particle impact in kinetic spray deposition is presented in Fig. 18, which is introduced in the research of Kang et al. (Ref 55).

After the impact and deposition stages, some refined grains are created by DRV and DRX, and the upper region of the deposited particle is somewhat strained (Fig. 18a). Additional heat energy is generated in sequence by subsequent particle impact, while subsidiary heat is transferred from successive particle impacts (Fig. 18b). As a result, microstructural alteration occurred at highly strained area by the static restoration processes (SRV and SRX) (Fig. 18c). It is important to note that the resultant microstructures can be sufficiently affected by the quantity of accumulated stored strain energy, which can be differentiated with the degree of plastic deformation. Some examples of the microstructures produced by SRV and SRX of the kinetic-sprayed Al deposit are presented in Fig. 19 (Ref 55).

As shown in Fig. 19, both static recovered and static recrystallized microstructures can be clearly observed in the kinetic-sprayed Al coating layer; however, it should be noted that SRV was the primary process in this kineticsprayed $\mathrm{Al}$ deposit. This is because these recovery and recrystallization phenomena have a competitive relationship since both of SRV and SRX consume stored strain energy during the reaction. The activation energy required for SRV was lower than for SRX, since the dislocation glide and climb was fairly active in high stacking fault energy (SFE) materials such as Al. Therefore, most of the stored strain energy was relieved through SRV (Ref 91-96).

To provide more generalized explanations, the microstructural reaction to the given thermal energy is considerably affected by the material properties and the degree of stored strain energy. Criteria for the occurrence of recovery and recrystallization such as temperature and stored energy (dislocation density) are different for the coating materials. The degree of freedom for dislocation movement is a crucial factor in recovery and recrystallization phenomena. Representatively, the SFE influences recovery and recrystallization and, in the case of high SFE material, recovery can be easily induced because dislocations are not dissociated into partial dislocations to avoid the creation of stacking fault. However, low SFE materials are highly sensitive to local conditions such as dislocation density, dislocation arrangement, and temperature 


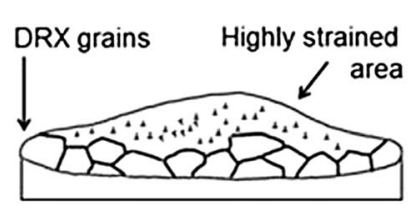

(a)

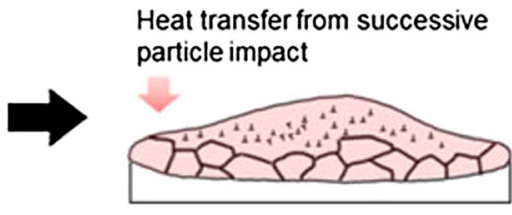

(b)

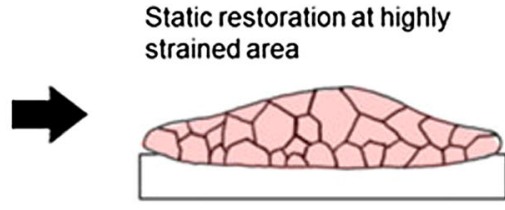

(c)

Fig. 18 The sequence of microstructural change via SRV and SRX during the kinetic spray: (a) microstructural state after the deposition stage, (b) additional heating by subsequent particle impact, and (c) microstructural change via SRV and SRX
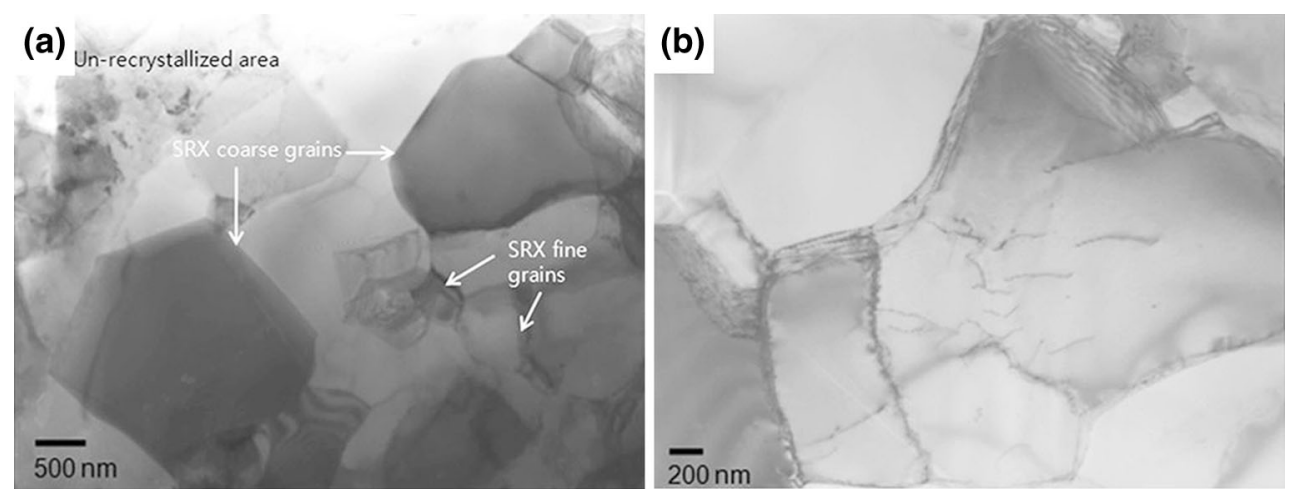

Fig. 19 TEM images of the kinetic-sprayed Al deposit: (a) newly formed grains created via SRX and (b) dislocation-annealed microstructure produced via SRV

increase. With regard to this, Borchers et al. investigated the interface microstructural difference of three kinds of kinetic-sprayed FCC metals ( $\mathrm{Al}, \mathrm{Ni}$ and $\mathrm{Cu}$ ) (Ref 61).

Figure 20 shows the distinctive interface microstructures of kinetic-sprayed $\mathrm{Al}, \mathrm{Cu}$, and $\mathrm{Ni}$. In the case of $\mathrm{Al}$ (Fig. 20a), some equiaxed nanocrystalline structures appeared near the interface region due to the dominant occurrence of recovery over recrystallization resulting from the high SFE of Al. As mentioned above, when the SFE is high, dislocations generated by particle impact hardly dissociate into partial dislocations to avoid producing stacking faults and dislocations move easily in a direction perpendicular to the slip plane at elevated temperatures, stimulating recovery. Also, tangled microstructures (marked A and B in Fig. 20a) and a wellbonded region where the interface is indistinguishable were formed in the vicinity of the interparticle interface.

The lower SFE in the Ni deposit (Fig. 20b) increased the difficulty of generating a recovery process, so the stored strain energy was primarily consumed by the recrystallization process. As a result, a uniform duplex structure comprised equiaxed nanosize grains on one side and microsize grains with coffee-bean-like contrasts on the other side was formed on the basis of deposited Ni particles interface. According to the research of Borchers et al., these coffee-bean-like structures resulted from the formation of intrinsic and extrinsic dislocation loops in some grains. Figure 21 shows the HRTEM images of coffeebean-like contrasts with dislocation loop in a kineticsprayed $\mathrm{Cu}$ deposit after the heat treatment for $1 \mathrm{~h}$ at $600{ }^{\circ} \mathrm{C}$. C. Borchers et al. infer that these intrinsic and extrinsic dislocation loops were likely created by the agglomeration of point defects, which resulted from the dislocation climb during or after the sequence of impacted particle plastic deformation (Ref 97).

Lastly, as shown in Fig. 20(c), the interfacial microstructure of kinetic-sprayed $\mathrm{Cu}$ was not uniform and various kinds of microstructures were produced after the deposition: relatively large grains with high dislocation density arranged in walls (A), elongated refined grains (B), equiaxed ultrafine grains (C), and micro-sized grains with recrystallization twins (D). Such various and non-uniform microstructures are attributed to lowest SFE of $\mathrm{Cu}$ among the $\mathrm{Al}, \mathrm{Ni}$, and $\mathrm{Cu}$. An extremely low SFE hinders the movement of the dislocations by inducing the dissociation of dislocations and, as a result, cross-slip and recovery are hard to occur. Accordingly, the microstructural evolution at the interface region of kinetic-sprayed $\mathrm{Cu}$ becomes determined by recrystallization rather than recovery, which is fairly dependent on local conditions such as dislocation density, dislocation orientation, dislocation arrangement, and local temperature.

Other types of microstructural change such as shear band and twin formation can occur near the severely deformed interface region. As mentioned above, high-strainrate deformation is fully concentrated at the interface region and, as a result, shear bands are usually generated by adiabatic shear localization (Ref 98). Particularly, at the moment of deposition, a number of shear bands are generated at the periphery of the interface region since that region is sufficiently susceptible to shear plastic deformation due to adiabatic shear instability. Figure 22 shows the shear bands generated in the kinetic-sprayed $\mathrm{Cu}$ deposit (marked with a white circle) (Ref 99).

Also, twin formation can occur in kinetic-sprayed coating layers when the SFE of the coating material is low and the following condition can be satisfied: 


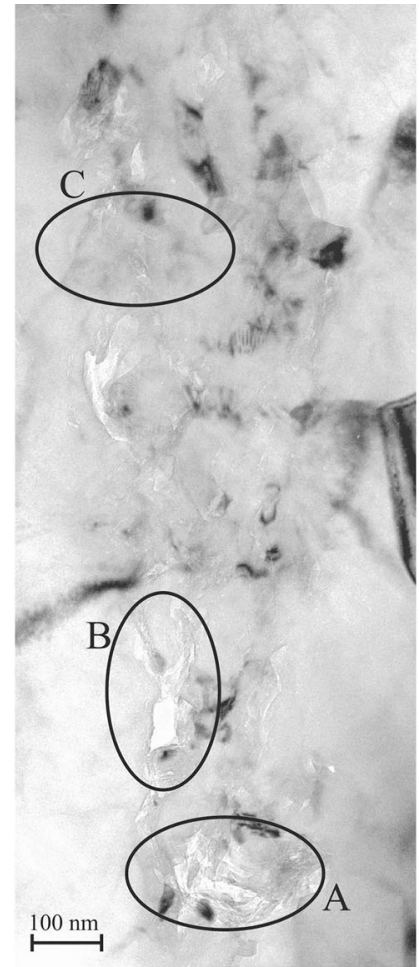

(a)
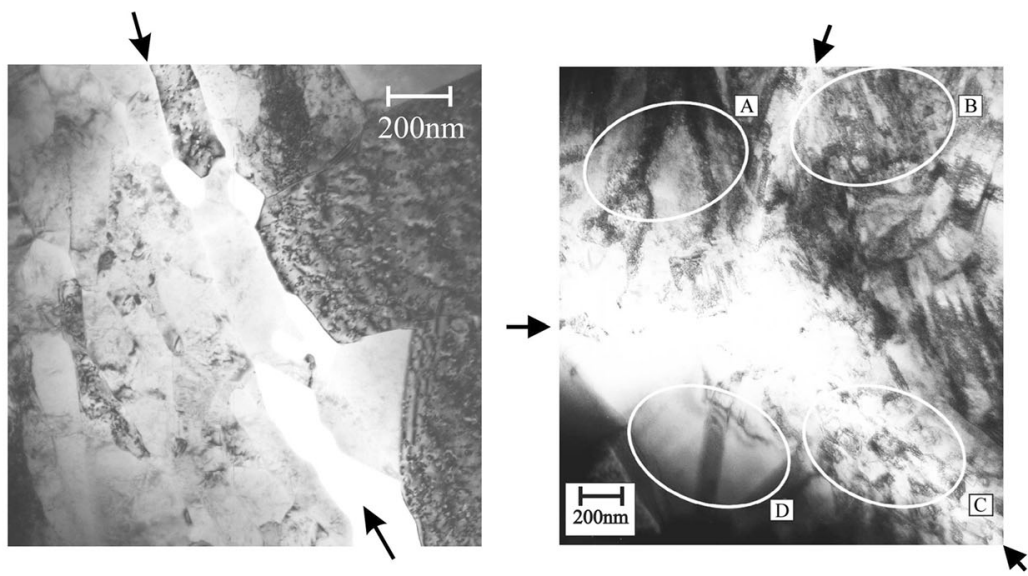

(c)

Fig. 20 TEM micrographs of kinetic-sprayed $\mathrm{Al}, \mathrm{Cu}$, and $\mathrm{Ni}$ deposit: (a) particle-particle boundary of $\mathrm{Al}$ coating layer from top to bottom, (b) triple joint of deposited Cu particles where the interparticle boundaries are marked with black arrows, and (c) particleparticle boundary of Ni deposit, where the interparticle boundaries are marked with black arrows
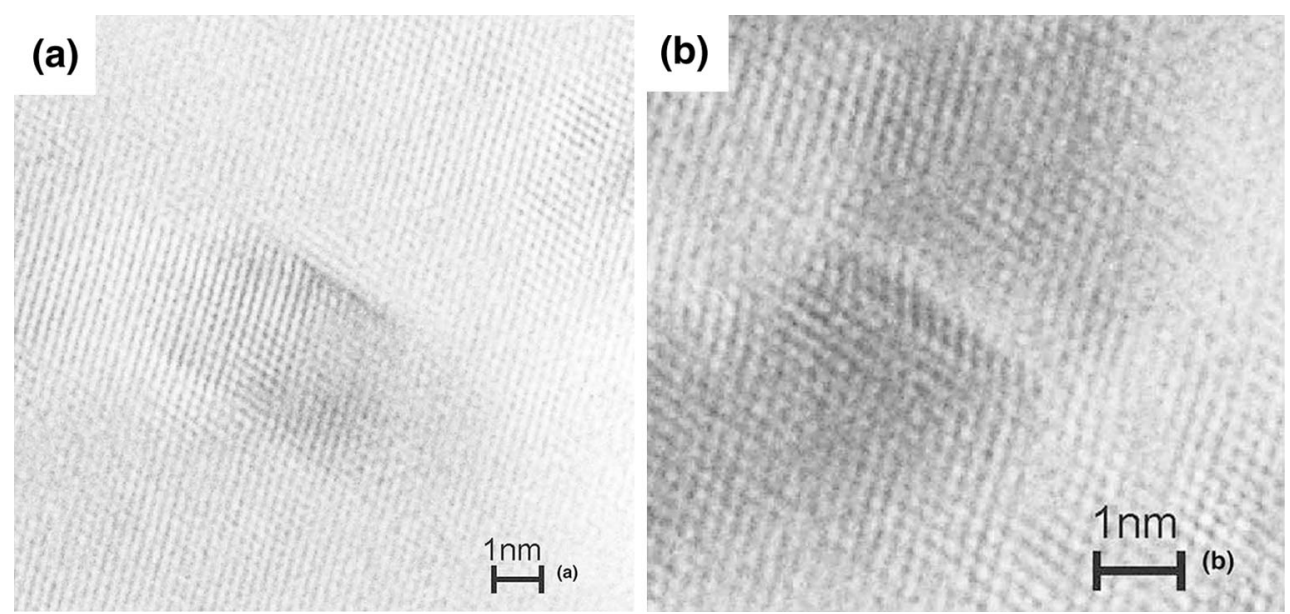

Fig. 21 HRTEM micrographs of coffee-bean-like contrasts in kinetic-sprayed copper deposit after a heat treatment for $1 \mathrm{~h}$ at $600{ }^{\circ} \mathrm{C}(\mathrm{a})$ intrinsic dislocation loop and (b) extrinsic dislocation loop

$$
\begin{aligned}
\sigma_{S} \geq & \sigma_{T} \\
\sigma_{S}= & \Delta \sigma_{G}^{\prime}+c_{2} \varepsilon^{-1 / 2} \exp \left(-c_{3}+c_{4} T \ln \dot{\varepsilon}\right)+k d^{-1 / 2} \\
& \sigma_{T}=\sigma_{0}+k d^{-1 / 2}
\end{aligned}
$$

where $\sigma_{S}$ is the slip stress, $\sigma_{T}$ is the twin stress, $\Delta \sigma_{G}^{\prime}$ is the contribution by solutes and initial dislocation density, $\varepsilon$ is the strain, $\dot{\varepsilon}$ is the strain rate, $k$ is the microstructural stress intensity, $d$ is the grain size, and $c_{2}, c_{3}, c_{4}$ are the material constants. According to the research of King et al. (Ref 52), the conditions suggested above are satisfied when the strain and strain rate are high, though the twinning stress was overestimated because of the effect of solute atoms in the material. However, this is a fairly unusual case, in which nano-twins were generated even in a relatively high 


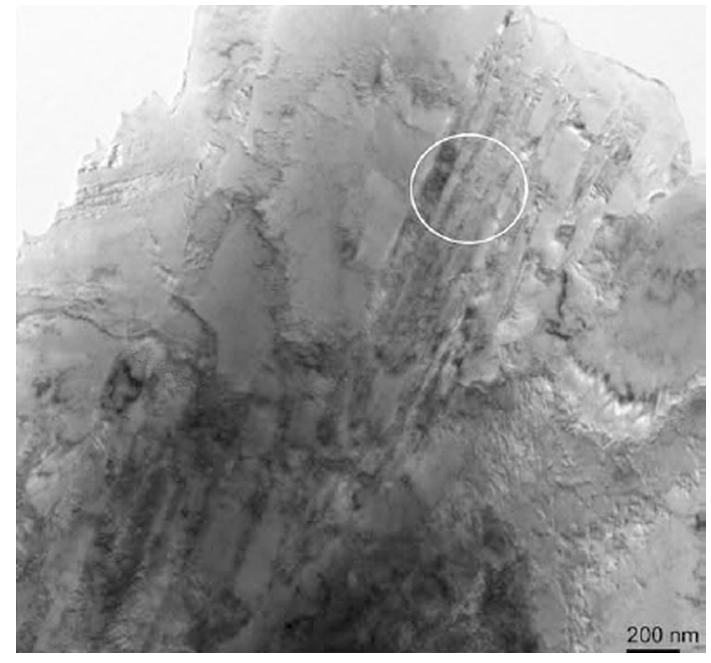

Fig. 22 Top-view TEM image of kinetic-sprayed $\mathrm{Cu}$ with shear bands (marked with a white arrow)

SFE material such as Ni (Ref 100). In this case, the contact stress estimated via FEM simulation was definitely lower than the calculated twinning stress determined using the above equation and thus the generation of nano-twins cannot be explained in terms of twinning stress. Bae et al. insisted that the primary cause of nano-twins in kineticsprayed Ni deposits was the lowered Zener-Hollomon parameter $(\mathrm{Z}=\dot{\varepsilon} \exp (Q / R T))$ by suppressed dislocation activity in newly created nanograins near the interface region (Ref 101). It was also inferred that a small quantity of solute atoms included in the feedstock $\mathrm{Ni}$ powder contributed to the reduction in dislocation mobility $(\mathrm{Cu})$ and in SFE (Co), resulting in the formation of nano-twins. Figure 23 shows the nano-twins formed in the kineticsprayed Ni coating layer. Narrow nano-twins (region 'i') and nano-twins bundles (region 'ii') can be clearly observed.

\subsection{Heat Treated Specimens}

In contrast to the as-sprayed specimen, microstructural changes in the heat treated specimen are generated throughout the entire specimen in the case of heat treated specimens, not only at the interface region, but also at the inner particle region, because of the supply of thermal energy to the entire specimen. The basic concept of the resultant microstructural evolution induced by heat treatment is identical to that of annealed bulk alloys. Figure 24 shows the sequence of microstructural changes in the kinetic-sprayed Al coating layer with extended heat treatment time (Ref 76).

Elongated grains produced by the high-velocity impact of $\mathrm{Al}$ particles were replaced by SRX grains after the heat treatment (Fig. 24b). These alternative SRX grains were gradually formed in accordance with increased heat treatment time (Fig. 24c), though grain growth eventually ceased in this case, at $2 \mathrm{~h}$. Figure 25 presents the obvious microstructural changes induced by heat treatment (Ref 76$)$.

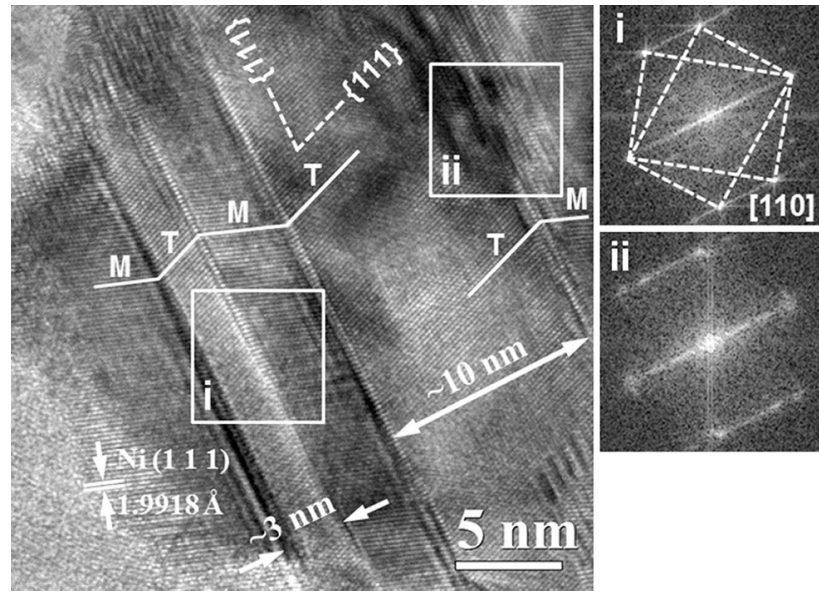

Fig. 23 High-magnification HRTEM image with diffraction fast Fourier transform (FFT) patterns of nano-twins generated in the kinetic-sprayed $\mathrm{Ni}$ deposit

Figure 25(a) shows the image quality (IQ) map of the as-sprayed $\mathrm{Al}$ coating layer. The region was divided from $\mathrm{A}$ to $\mathrm{C}$, from the inner region to the interface region. The overall IQ was poor in this case due to the severe plastic deformation of particles. Especially, the region ' $\mathrm{C}$ ' showed the poorest IQ due to extremely high dislocation density; however, a clear IQ map was obtained after heat treatment by decreased dislocation density resulting from SRV, SRX, and grain growth (Fig. 25b). It is important to note that the microstructure of the interface region was similar to that of the inner particle region. This means that microstructural changes occurred more rapidly at the interface region than at the inner particle region due to higher stored strain energy.

Nevertheless, the microstructural changes at the interface region are more dynamic than at the inner region of the deposited particles. Although the high strain energy at the interface region is consumed by strain-energy-relieving phenomena such as DRV, DRX, SRV, and SRX during the deposition stage, a great number of dislocations still remain near the interface region. Thus, SRV, SRX, and grain growth occur more actively at the interface region to relieve the remaining stored strain energy. Besides, it should be noticed that the microstructural changes can be sufficiently different even for the identical heat treatment conditions, in accordance with the kinetic spray process conditions and with the material properties, which affect the impact behavior and stored energy relieving behavior of particles. Also, as mentioned in section 5.1, different material properties (i.e., SFE) result in distinctive microstructural evolution because of their influence on the dislocation behavior (Ref 80).

Additional metallurgical/diffusion bonding is created after heat treatment at the mechanically bonded interface by a diffusion of elements in the coating layer. As a result, the adhesive (particle-substrate) and cohesive (particleparticle) bonding is highly enhanced relative to the as-sprayed specimen. As mentioned in section 2.2, some 

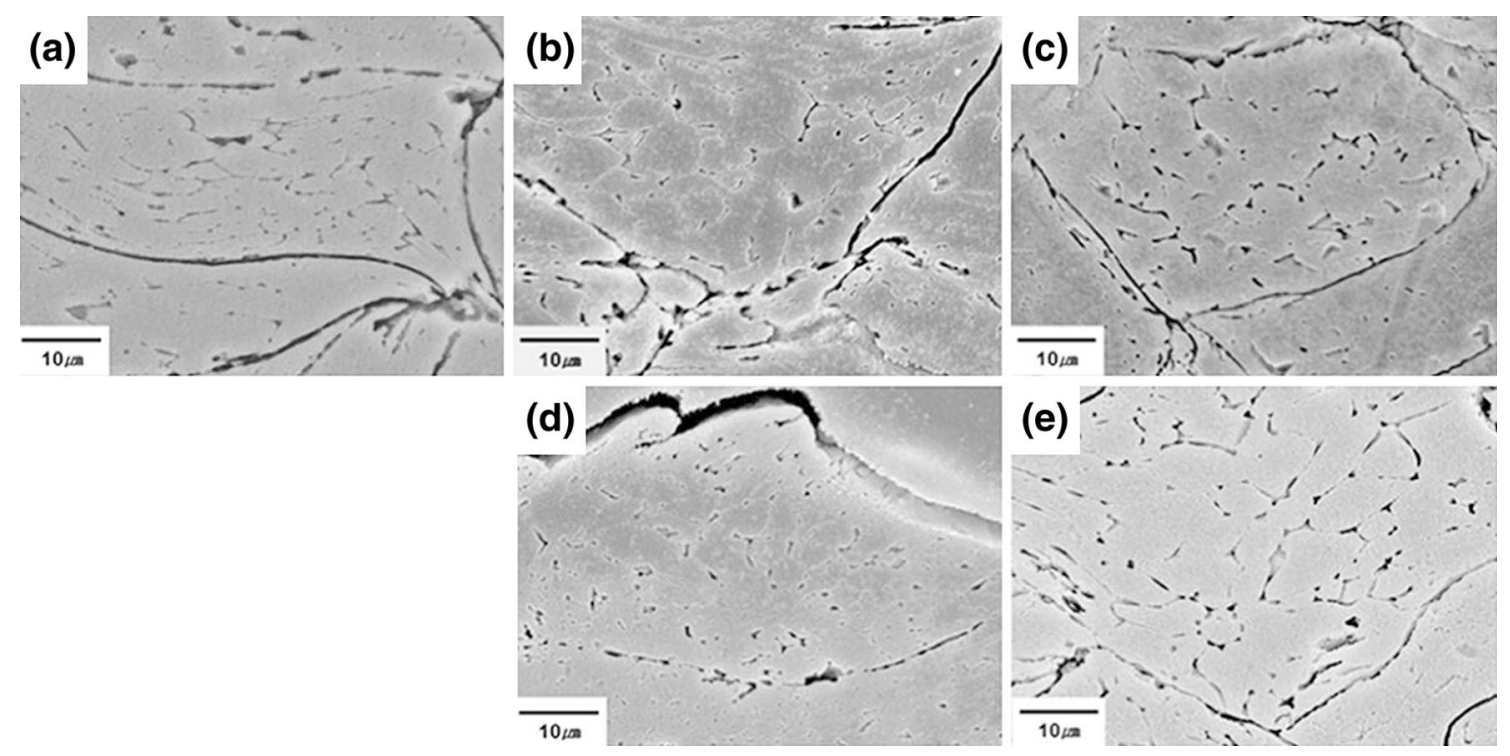

Fig. 24 Etched cross-sectional SEM images of kinetic-sprayed Al coatings: (a) as-sprayed and heat treated for (b) 1 h, (c) 2 h, (d) 3 h, and (e) $4 \mathrm{~h}$
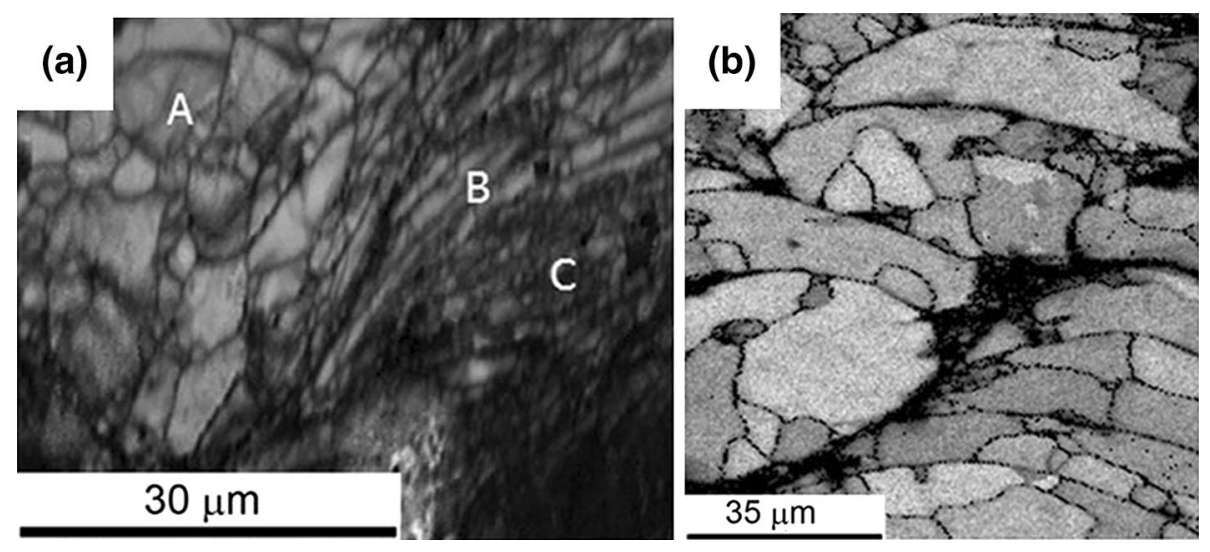

Fig. 25 IQ maps of kinetic-sprayed Al deposit: (a) as-sprayed and (b) heat treated for $4 \mathrm{~h}$

phase changes can occur such as the formation of intermetallic compounds.

\section{Summary}

Since kinetic-sprayed particles are deposited primarily via kinetic energy without the use of a thermal energy source, the microstructure of kinetic-sprayed coating layer differs highly from that of thermal-sprayed coating layers. Significant researches into the microstructural evolution of kinetic-sprayed coatings have occurred over recent years. According to this body of researches, the primary factors influencing the microstructure of kinetic spray are the lack of heat source and the high kinetic energy of the deposited particles. Crystal phase transformations and chemical reaction rarely occur because the particles are not heated directly by a thermal energy source. The high level of kinetic energy produces severe plastic deformation of the deposited particles. This results in a high-density coating layer with low porosity, though some micro-cracks are occasionally induced at the interparticle boundary or inner region of particles. Specifically, at the vicinity of the particle-particle or particle-substrate interface region, quite distinctive microstructures are produced compared to the inner particle region due to high-strain and high-strain-rate plastic deformation and a high degree of instantly induced thermal energy. These factors result in crystal phase transformations such as amorphization, crystallization, the formation of intermetallic compounds, and microstructural change caused by DRV, DRX, SRV, and SRX.

\section{Acknowledgments}

This work was supported by a grant from the National Research Foundation of Korea (NRF) funded by the 
Korean government (MEST) (NRF-2014R1A2A2A0 5007633).

\section{References}

1. A.P. Alkhimov, A.N. Papyrin, V.F. Kosarev, N.I. Nesterovich, and M.M. Shushpanov, Gas-Dynamic Spray Method for Applying a Coating, US Patent 5,302,414; April 12, 1994

2. R.C. Dykhuizen and M.F. Smith, Gas Dynamic Principles of Cold Spray, J. Therm. Spray Technol., 1998, 7(2), p 205-212

3. V.F. Kosarev, S.V. Klinkov, A.P. Alkhimov, and A.N. Papyrin, On Some Aspects of Gas Dynamics of the Cold Spray Process, $J$. Therm. Spray Technol., 2003, 12(2), p 265-281

4. A.P. Alkhimov, V.F. Kosarev, and S.V. Klinkov, The Features of Cold Spray Nozzle Design, J. Therm. Spray Technol., 2001, 10(2), p 375-381

5. M. Grujicic, C.L. Zhao, C. Tong, W.S. DeRosset, and D. Helfritch, Analysis of the Impact Velocity of Powder Particles in the Cold-Gas Dynamic-Spray Process, Mater. Sci. Eng. A, 2004, 368, p 222-230

6. B. Jodoin, Cold Spray Nozzle Mach Number Limitation, $J$. Therm. Spray Technol., 2002, 11(4), p 496-507

7. W.-Y. Li and C.-J. Li, Optimal Design of a Novel Cold Spray Gun Nozzle at a Limited Space, J. Therm. Spray Technol., 2005, 14(3), p 391-396

8. H.-B. Jung, J.-I. Park, S.-H. Park, H.-J. Kim, C. Lee, and J.-W. Han, Effect of the Expansion Ratio and Length Ratio on a GasParticle Flow in a Converging-Diverging Cold Spray Nozzle, Met. Mater. Int., 2009, 15, p 967-970

9. H. Assadi, F. Gartner, T. Stoltenhoff, and H. Kreye, Bonding Mechanism in Cold Gas Spraying, Acta Mater., 2003, 51, p 43794394

10. T. Schmidt, F. Gartner, H. Assadi, and H. Kreye, Development of Generalized Parameter Window for Cold Spray Deposition, Acta Mater., 2006, 54, p 729-742

11. G. Bae, Y. Xiong, S. Kumar, K. Kang, and C. Lee, General Aspects of Interface Bonding in Kinetic Sprayed Coatings, Acta Mater., 2008, 56, p 4858-4868

12. G. Bae, S. Kumar, S. Yoon, K. Kang, H. Na, H. Kim, and C. Lee, Bonding Features and Associated Mechanisms in Kinetic Sprayed Titanium Coatings, Acta Mater., 2009, 57, p 5654-5666

13. M. Grujicic, C.L. Zhao, W.S. DeRosset, and D. Helfritch, Adiabatic Shear Instability Based Mechanism for Particles/Substrate Bonding in the Cold-Gas Dynamic-Spray Process, Mater. Des. 2004, 25, p 681-688

14. T. Hussain, D.G. McCartney, P.H. Shipway, and T. Marrocco, Corrosion Behavior of Cold Sprayed Titanium Coatings and Free Standing Deposit, J. Therm. Spray Technol., 2011, 20(1-2), p 260274

15. D. Dzhurinskiy, E. Maeva, E. Leshchinsky, and R.G. Maev, Corrosion Protection of Light Alloys Using Low Pressure Cold Spray, J. Therm. Spray Technol., 2012, 21(2), p 302-313

16. W.B. Choi, L. Li, V. Luzin, R. Neiser, T. Gnaupel-Herold, H.J. Prask, S. Sampath, and A. Gouldstone, Integrated Characterization of Cold Sprayed Aluminum Coatings, Acta Mater., 2007, $\mathbf{5 5}, \mathrm{p} 857-866$

17. F. Gartner, T. Stoltenhoff, J. Voyer, H. Kreye, S. Riekehr, and M. Kocak, Mechanical Properties of Cold-Sprayed and Thermally Sprayed Copper Coatings, Surf. Coat. Technol., 2006, 200, p 67706782

18. Y. Tao, T. Xiong, C. Sun, L. Kong, X. Cui, T. Li, and G.-L. Song, Microstructure and Corrosion Performance of a Cold Sprayed Aluminum Coating on AZ91D Magnesium Alloy, Corros. Sci., 2010, 52, p 3191-3197

19. P. Richer, M. Yandouzi, L. Beauvais, and B. Jodoin, Oxidation Behavior of CoNiCrAlY Bond Coats Produced by Plasma, HVOF and Cold Gas Dynamic Spraying, Surf. Coat. Technol., 2010, 204, p 3962-3974

20. S.B. Pitchuka, D. Lahiri, G. Sundararajan, and A. Agarwal, Scratch-induced Deformation Behavior of Cold-sprayed Alumi- num Amorphous/Nanocrystalline Coatings at Multiple Load Scales, J. Therm. Spray Technol., 2014, 23(3), p 502-513

21. Q. Zhang, C.-J. Li, C.-X. Li, G.-J. Yang, and S.-C. Lui, Study of Oxidation Behavior of Nanostructured NiCrAlY Bond Coatings Deposited by Cold Spraying, Surf. Coat. Technol., 2008, 202, p 3378-3384

22. H.-J. Kim, C. Lee, and S.-Y. Hwang, Superhard Nano WC$12 \%$ Co Coatings by Cold Spray Deposition, Mater. Sci. Eng. A, 2005, 391, p 243-248

23. A. Manap, A. Nakano, and K. Ogawa, The Protectiveness of Thermally Grown Oxides on Cold Sprayed CoNiCrAlY Bond Coat in Thermal Barrier Coating, J. Therm. Spray Technol., 2012, 21(3-4), p 586-596

24. R.Gr Maev and V. Leshchynsky, Air Gas Dynamic Spraying of Powder Mixtures: Theory and Application, J. Therm. Spray Technol., 2006, 15(2), p 198-205

25. E. Irissou, J.-G. Legoux, A.N. Ryabinin, B. Jodoin, and C. Moreau, Review on Cold Spray Process and Technology: Part I-Intellectual Property, J. Therm. Spray Technol., 2008, 17(4), p 495-516

26. H. Singh, T.S. Sidhu, and S.B.S. Kalsi, Cold Spray Technology: Future of Coating Deposition Processes, Frattura ed Integrita Strutturale, 2012, 22, p 69-84

27. J. Karthikeyan, Cold Spray Technology: International Status and USA Efforts, ASB Industries, December, 2004

28. N.P. Padture, M. Gell, and E.H. Jordan, Thermal Barrier Coatings for Gas-Turbine Engine Applications, Science, 2002, 12, p 280-284

29. T. Nakamura, G. Qian, and C.C. Berndt, Effects of Pores on Mechanical Properties of Plasma-sprayed Ceramic Coatings, $J$. Am. Ceram. Soc., 2000, 83(3), p 578-584

30. T.-C. Jen, L. Li, W. Cui, Q. Chen, and X. Zhang, Numerical Investigations on Cold Gas Dynamic Spray Process with Nanoand Microsize Particles, Int. J. Heat Mass Transf., 2005, 48, p 4384-4396

31. X.K. Suo, T.K. Liu, W.Y. Li, Q.L. Suo, M.P. Planche, and H.L. Liao, Numerical Study on the Effect of Nozzle Dimension on Particle Distribution in Cold Spraying, Surf. Coat. Technol., 2013, 220, p 107-111

32. J. Pattison, S. Celotto, A. Khan, and W. O'Neill, Standoff Distance and Bow Shock Phenomena in the Cold Spray Process, Surf. Coat. Technol., 2008, 202, p 1443-1454

33. H. Tabbara, S. Gu, D.G. McCartney, T.S. Price, and P.H. Shipway, Study on Process Optimization of Cold Gas Spraying, $J$. Therm. Spray Technol., 2011, 20(3), p 608-620

34. S.H. Zahiri, C.I. Antonio, and M. Jahedi, Elimination of Porosity in directly Fabricated Titanium Via Cold Gas Dynamic Spraying, J. Mater. Process. Technol., 2009, 209, p 922-929

35. J. Lee, S. Shin, H.-J. Kim, and C. Lee, Effect of Gas Temperature on Critical Velocity and Deposition Characteristics in Kinetic Spraying, Appl. Surf. Sci., 2007, 253, p 3512-3520

36. C.-J. Li and W.-Y. Li, Deposition Characteristics of Titanium Coating in Cold Spraying, Surf. Coat. Technol., 2003, 167, p 278283

37. S. Shin, S. Yoon, Y. Kim, and C. Lee, Effect of Particle Parameters on the Deposition Characteristics of a Hard/Soft Particles Composite in Kinetic Spraying, Surf. Coat. Technol., 2006, 201, p 3457-3461

38. W. Wong, E. Irissou, A.N. Ryabinin, J.-G. Legoux, and S. Yue, Influence of Helium and Nitrogen Gases on the Properties of Cold Gas Dynamic Sprayed Pure Titanium Coatings, J. Therm. Spray Technol., 2011, 20(1-2), p 213-226

39. G. Bae, K. Kang, H. Na, J.-J. Kim, and C. Lee, Effect of Particle Size on the Microstructure and Properties of Kinetic Sprayed Nickel Coatings, Surf. Coat. Technol., 2010, 204, p 3326-3335

40. G. Bae, J. Jang, and C. Lee, Correlation of Particle Impact Conditions with Bonding, Nanocrystal Formation and Mechanical Properties in Kinetic Sprayed Nickel, Acta Mater., 2012, 60, p 3524-3535

41. K. Kang, S. Yoon, Y. Ji, and C. Lee, Oxidation Dependency of Critical Velocity for Aluminum Feedstock Deposition in Kinetic Spraying Process, Mater. Sci. Eng. A, 2008, 486, p 300-307 
42. W.-Y. Li, C.-J. Li, and H. Liao, Significant Influence of Particle Surface Oxidation on Deposition Efficiency, interface Microstructure and Adhesive Strength of Cold-sprayed Copper Coatings, Appl. Surf. Sci., 2010, 256, p 4953-4958

43. W.-Y. Li, C. Zhang, X.P. Guo, G. Zhang, H.L. Liao, C.-J. Li, and C. Coddet, Effect of Standoff Distance on Coating Deposition Characteristics in Cold Spraying, Mater. Des., 2008, 29, p 297-304

44. K. Binder, J. Gottschalk, M. Kollenda, F. Gartner, and T. Klassen, Influence of Impact Angle and Gas Temperature on Mechanical Properties of Titanium Cold Spray Deposits, $J$. Therm. Spray Technol., 2011, 20(1-2), p 234-242

45. T. Han, Z. Zhao, B.A. Gillispie, and J.R. Smith, Effeects of Spray Conditions on Coating Formation by the Kinetic Spray Process, $J$. Therm. Spray Technol., 2005, 14(3), p 373-383

46. T. Stoltenhoff, H. Kreye, and H.J. Richter, An Analysis of the Cold Spray Process and Its Coatings, J. Therm. Spray Technol., 2002, 11(4), p 542-550

47. X.-K. Wu, X.-L. Zhou, H. Cui, X. Zheng, and J.-S. Zhang, Deposition Behavior and Characteristics of Cold-sprayed $\mathrm{Cu}-\mathrm{Cr}$ Composite Deposits, J. Therm. Spray Technol., 2012, 21(5), p 792-799

48. X.K. Suo, X.P. Guo, W.-Y. Li, M.P. Planche, and H.L. Liao, Investigation of Deposition Behavior of Cold-Sprayed Magnesium Coating, J. Therm. Spray Technol., 2012, 21(5), p 831-837

49. L. Ajdelsztajn, B. Jodoin, G.E. Kim, and J.M. Schoenung, Cold Spray Deposition of Nanocrystalline Aluminum Alloys, Metall. Mater. Trans. A, 2005, 36A, p 657-666

50. X.L. Zhou, S.J. Mou, X.K. Wu, and J.S. Zhang, Deposition Behavior of Mixed Binary Metallic Powders in Cold Spraying Process, Appl. Surf. Sci., 2011, 257, p 10628-10633

51. R.S. Lima, J. Karthikeyan, C.M. Kay, J. Lindemann, and C.C. Berndt, Microstructural Characteristics of Cold-Sprayed Nanostructured WC-Co Coatings, Thin Solid Films, 2002, 416, p 129-135

52. P.C. King, S.H. Zahiri, and M. Jahedi, Microstructural Refinement within a Cold-Sprayed Copper Particle, Metall. Mater. Trans. A, 2009, 40A, p 2115-2123

53. C. Borchers, F. Gartner, T. Stoltenhoff, H. Assadi, and H. Kreye, Microstructural and Macroscopic Properties of Cold Sprayed Copper Coatings, J. Appl. Phys., 2003, 93, p 10064-10070

54. Q. Wang, N. Birbilis, and M.-X. Zhang, Interfacial Structure Between Particles in an Aluminum Deposit Produced by Cold Spray, Mater. Lett., 2011, 65, p 1576-1578

55. K. Kang, J. Won, G. Bae, S. Ha, and C. Lee, Interfacial Bonding and Microstructural Evolution of $\mathrm{Al}$ in Kinetic Spraying, J. Mater. Sci., 2012, 47, p 4649-4659

56. G. Bae, K. Kang, J.-J. Kim, and C. Lee, Nanostructure Formation and Its Effects on the Mechanical Properties of Kinetic Sprayed Titanium Coating, Mater. Sci. Eng. A, 2010, 527, p 6313-6319

57. Y. Zou, W. Qin, E. Irissou, J.-G. Legoux, S. Yue, and J.A. Szpunar, Dynamic Recrystallization in the Particle/Particle Interfacial Region of Cold-Sprayed Nickel Coating: Electron Backscatter Diffraction Characterization, Scr. Mater., 2009, 61, p 899-902

58. D. Rafaja, T. Schucknecht, V. Klemm, A. Paul, and H. Barek, Microstructural Characterization of Titanium Coatings Deposited using Cold Gas Spraying on $\mathrm{Al}_{2} \mathrm{O}_{3}$ Substrates, Surf. Coat. Technol., 2009, 203, p 3206-3213

59. C. Moy, J. Cairnet, G. Ranzi, M. Jahedi, and S.P. Ringer, Investigating the Microstruture and Composition of Cold Gasdynamic Spray (CGDS) Ti powder Deposited on Al 6063 Substrate, Surf. Coat. Technol., 2010, 204, p 3739-3749

60. Y.Y. Zhang and J.S. Zhang, Recrystallization in the Particles Interfacial Region of the Cold-Sprayed Aluminum Coating: Strain-Induced Boundary Migration, Mater. Lett., 2011, 65, p $1856-1858$

61. C. Borchers, F. Gartner, T. Stoltenhoff, and H. Kreye, Microstructural Bonding Features of Cold Sprayed Face Centered Cubic Metals, J. Appl. Phys., 2004, 96, p 4288-4292

62. Y. Zou, D. Goldbaum, J.A. Szpunar, and S. Yue, Microstructure and Nanohardness of Cold-Sprayed Coatings: Electron Backscattered Diffraction and Nanoindentation Studies, Scr. Mater. 2010, 62, p 395-398
63. Y. Xion, K. Kang, G. Bae, S. Yoon, and C. Lee, Dynamic Amorphization and Recrystallization of Metals in Kinetic Spray Process, Appl. Phys. Lett., 2008, 92, p 194101

64. S. Yoon, G. Bae, Y. Xiong, S. Kumar, K. Kang, J.-J. Kim, and C. Lee, Strain-enhanced Nanocrystallization of a CuNiTiZr Bulk Metallic Glass Coating by a Kinetic Spraying Process, Acta Mater., 2009, 57, p 6191-6199

65. S. Guetta, M.H. Berger, F. Borit, V. Guipont, M. Jeandin, M. Boustie, Y. Ichikawa, K. Sakaguchi, and K. Ogawa, Influence of Particle Velocity on Adhesion of Cold-Sprayed Splats, J. Therm. Spray Technol., 2009, 18, p 331-342

66. H. Lee, S. Lee, and K. Ko, Annealing Effects on the Intermetallic Compound Formation of Cold Sprayed Ni, Al Coatings, J. Mater. Process. Technol., 2009, 209, p 937-943

67. X.-J. Ning, J.-H. Kim, H.-J. Kim, and C. Lee, Characteristics and Heat Treatment of Cold-sprayed Al-Sn Binary Alloy Coatings, Appl. Surf. Sci., 2009, 255, p 3933-3939

68. G.-J. Yang, H.-T. Wang, C.-J. Li, and C.-X. Li, Effect of Annealing on the Microstructure and Erosion Performance of Cold-Sprayed FeAl Intermetallic Coatings, Surf. Coat. Technol., 2011, 205, p 5502-5509

69. W.-Y. Li, C.-J. Li, and H. Liao, Effect of Annealing Treatment on the Microstructure and Properties of Cold-Sprayed $\mathrm{Cu}$ Coating, J. Therm. Spray Technol., 2006, 15(2), p 206-211

70. H. Bu, M. Yandouzi, C. Ju, and B. Jodoin, Effect of Heat Treatment on the Intermetallic Layer of Cold Sprayed Aluminum Coatings on Magnesium Alloy, Surf. Coat. Technol., 2011, 205, p 4665-4671

71. W.-Y. Li, C.-J. Li, H. Liao, and C. Coddet, Effect of Heat Treatment on the Microstructure and Microhardness of Coldsprayed Tin Bronze Coating, Appl. Surf. Sci., 2007, 253, p 59675971

72. H.-T. Wang, C.-J. Li, G.-J. Yang, and C.-X. Li, Effect of Heat Treatment on the Microstructure and Property of Cold-sprayed Nanostructured $\mathrm{FeAl} / \mathrm{Al}_{2} \mathrm{O}_{3}$ Intermetallic Composite Coating, Vacuum, 2009, 83, p 146-152

73. H. Lee, S. Jung, S. Lee, and K. Ko, Fabrication of Cold Sprayed Al-Intermetallic Compounds Coatings by Post Annealing, Mater. Sci. Eng. A, 2006, 433, p 139-143

74. T. Novoselova, S. Celotto, R. Morgan, P. Fox, and W. O'Neill, Formation of TiAl Intermetallics by Heat Treatment of Coldsprayed Precursor Deposits, J. Alloys Compd., 2007, 436, p 69-77

75. K. Spencer and M.-X. Zhang, Heat Treatment of Cold Sprayings to Form Protective Intermetallic Layers, Scr. Mater., 2009, 61, p 44-47

76. K. Kang, H. Park, G. Bae, and C. Lee, Microstructure and Texture of $\mathrm{Al}$ Coating during Kinetic Spraying and Heat Treatment, J. Mater. Sci., 2012, 47, p 4053-4061

77. P.D. Eason, J.A. Fewkes, S.C. Kennett, T.J. Eden, K. Tello, M.J. Kaufman, and M. Tiryakioglu, On the Characterization of Bulk Copper Produced by Cold Gas Dynamic Spray Processing in as Fabricated and Annealed Conditions, Mater. Sci. Eng. A, 2011, 528, p 8174-8178

78. S.H. Zahiri, D. Fraser, and M. Jahedi, Recrystallization of Cold Spray-Fabricated CP Titanium Structures, J. Therm. Spray Technol., 2009, 18(1), p 16-22

79. A.C. Hall, D.J. Cook, R.A. Neiser, T.J. Roemer, and D.A. Hirschfeld, The Effect of a Simple Annealing Heat Treatment on the Mechanical Properties of Cold-sprayed Aluminum, J. Therm. Spray Technol., 2006, 15(2), p 233-238

80. E. Calla, D.G. McCartney, and P.H. Shipway, Effect of Deposition Conditions on the Properties and Annealing Behavior of Cold-Sprayed Copper, J. Therm. Spray Technol., 2006, 15, p 255262

81. T. Schmidt, H. Assadi, F. Gartner, H. Richter, T. Stoltenhoff, H. Kreye, and T. Klassen, From Particle Acceleration to Impact and Bonding in Cold Spraying, J. Therm. Spray Technol., 2009, 18(56), p 794-808

82. S. Yoon, H. Kim, and C. Lee, Deposition Behavior of Bulk Amorphous NiTiZrSiSn According to the Kinetic and Thermal Energy Levels in the Kinetic Spraying Process, Surf. Coat. Technol., 2006, 200, p 6022-6029 
83. H. Lee, S. Lee, H. Shin, and K. Ko, Mechanical Matching and Microstructural Evolution at the Coating/Substrate Interfaces of Cold-sprayed Ni, Al Coatings, J. Alloys Compd., 2009, 478, p 636641

84. M. Grujicic, J.R. Saylor, D.E. Beasley, W.S. DeRosset, and D. Helfritch, Computational Analysis of the Interfacial Bonding Between Feed-Powder Particles and the Substrate in the ColdGas Dynamic-Spray Process, Appl. Surf. Sci., 2003, 219, p 211-227

85. Y. Xiong, G. Bae, X. Xiong, and C. Lee, The Effects of Successive Impacts and Cold Welds on the Deposition Onset of Cold Spray Coatings, J. Therm. Spray Technol., 2010, 19, p 575-585

86. E. Nes, Modelling of Work Hardening and Stress Saturation in FCC Metals, Prog. Mater. Sci., 1998, 41, p 129-193

87. E. Nes, T. Pettersen, and K. Marthinsen, On the Mechanisms of Work Hardening and Flow-Stress Saturation, Scr. Mater., 2000, 43, p 55-62

88. E. Nes and K. Marthinsen, Modeling the Evolution in Microstructure and Properties During Plastic Deformation of F.C.C.Metals and Alloys-An Approach Towards a Unified Model, Mater. Sci. Eng. A, 2002, 322, p 176-193

89. E. Nes, K. Marthinsen, and Y. Brechet, On the Mechanisms of Dynamic Recovery, Scr. Mater., 2002, 47, p 607-611

90. L.E. Murr, K.P. Staudhammer, and M.A. Meyers, Metallurgical Applications of Shock-Wave and High-Strain-Rate Phenomena, Elsevier, Amsterdam, 1995

91. F.J. Humphreys and M. Hatherly, Recrystallization and Related Annealing Phenomena, Elsevier, Oxford, 2004
92. N. Hansen, X. Huang, M. Moller, and A. Godfrey, Thermal Stability of Aluminum Cold Rolled to Large Strain, J. Mater. Sci., 2008, 43, p 6254-6259

93. R.A. Vandermeer and N. Hansen, Recovery Kinetics of Nanostructured Aluminum; Model and Experiment Original Research Article, Acta Mater., 2008, 56, p 5719-5727

94. H.J. McQueen, Elevated-temperature Deformation at Forming Rates of $10^{-2}$ to $10^{2} \mathrm{~s}^{-1}$, Metall. Mater. Trans. A, 2002, 33, $\mathrm{p} 345-362$

95. H. Hu, Recrystallization of Metals, Gordon, New York, 1963

96. T. Hasegawa, T. Yakou, and U.F. Kocks, Length Changes and Stress Effects during Recovery of Deformed Aluminum, Acta Metall., 1982, 30, p 235-243

97. C. Borchers, F. Gartner, T. Stoltenhoff, and H. Kreye, Formation of Persistent Dislocation Loops by Ultra-High Strain-Rate Deformation During Cold Spraying, Acta Mater., 2005, 53, p 2991-3000

98. M.A. Meyers, Y.B. Xu, Q. Xue, M.T. Perez-Prado, and T.R. McNelley, Microstructural Evolution in Adiabatic Shear Localization in Stainless Steel, Acta Mater., 2003, 51, p 1307-1325

99. H. Koivuluoto, M. Honkanen, and P. Vuoristo, Cold-Sprayed Copper and Tantalum Coatings-Detailed FESEM and TEM Analysis, Surf. Coat. Technol., 2010, 204, p 2353-2361

100. G. Bae, K. Kang, and C. Lee, Nanoscale Deformation Twinning at Ultrahigh Strain Rates During Kinetic Spraying of Nickel, Mater. Lett., 2012, 89, p 320-323

101. C. Zener and H. Hollomon, Effect of Strain Rate Upon Plastic Flow of Steel, J. Appl. Phys., 1944, 15, p 22-32 